\title{
EL DESEMPEÑO EN JUICIO DE LA FNE: ¿ES REALMENTE UN MEJOR LITIGANTE QUE LOS DEMANDANTES PRIVADOS?*
}

\author{
Diego G. PARDOW**
}

RESUMEN: Este documento analiza el desempeño como litigante de la Fiscalía Nacional Económica ("FNE"), proponiendo un enfoque que sistematiza sus diferencias con los demandantes privados en términos del esfuerzo que cada uno debiera desplegar en un juicio. A partir de la base de datos del Tribunal de la Libre Competencia, se utiliza la presencia de la FNE como una manera de dividir los perfiles de demandante entre público y privado, mientras que el número de audiencias se utiliza para medir la intensidad de la disputa. Los resultados reflejan que la FNE tiene efectivamente más éxito que los privados en una gran cantidad de casos donde el nivel de intensidad de la disputa es relativamente bajo. Sin embargo, en la minoría de casos donde el nivel de disputa es relativamente alto, son los demandantes privados quienes muestran un mejor desempeño. Este trabajo argumenta que la razón se relaciona con los costos de agencia. Mientras los privados tendrían costos de agencia variables, que dependen del número de partes que resulte necesario coordinar, la FNE funcionaría con una estructura burocrática de costos relativamente más constantes. Ello hace que la FNE tenga ventajas comparativas en juicios como la colusión donde el daño está disperso entre una multitud de consumidores. En contraste, los privados tienen ventajas comparativas en casos como la dominancia, donde el número de partes involucradas es reducido. A diferencia de estudios anteriores, el trabajo concluye que la superioridad de la FNE es relativa, y por ello, la política pública debiera fomentar la división del trabajo. Fortalecer a la FNE a expensas de la litigación privada parece derechamente una mala idea. Los mecanismos de fiscalización público y privado no deben ser mirados como sustitutos estructurales, sino como complementos estratégicos.

PALABRAS CLAVE: Libre Competencia - Fiscalización - Litigio

Fecha de recepción: 2 de abril de 2015.

Fecha de aceptación: 27 de agosto de 2015.

** Abogado, Universidad de Chile (CHILE). Magíster y Doctor en Derecho, Universidad de California, Berkeley (EE.UU.) Profesor del Departamento de Derecho Económico, Facultad de Derecho, Universidad de Chile (CHILe). Agradezco sus comentarios a Eric Talley, Prasad Krishnamurthy, Ernesto Muñoz, Diego Hernández y los participantes de la WELS Conference de 2014. Cualquier error es de mi exclusiva responsabilidad. Correo electrónico: dpardow@berkeley.edu 


\title{
The Perfomance of The Antitrust Prosecutor's OFFICE: IS REALLY PUBLIC ENFORCEMENT SUPERIOR TO PRIVATE ENFORCEMENT?
}

\begin{abstract}
This paper evaluates the performance on antitrust cases of the Chilean public enforcer (FNE by its acronym in Spanish). It presents an approach that frames its differences with private plaintiffs in terms of the effort that each of these mechanisms of enforcement should deliver during the trial. In a particular case, the presence of the FNE is used to draw the line between public and private enforcement, while the number of hearings is considered as a proxy of the joint effort delivered by the parties. The results show that the FNE outperforms private plaintiffs in a large number of cases where the effort of the parties is relatively low. However, within a small number of cases where the parties deliver a relatively high effort, the private plaintiffs are the ones who perform better. The paper argues that these trends are related with the structure of agency costs. Whereas private plaintiffs face a variable cost, depending on the number of victims whose coordination is required, the FNE works as a bureaucratic organization that has rather constant costs. The FNE has thus a comparative advantage in prosecuting offenses that involve a large number of victims, such as collusion. In contrast, private plaintiffs have the edge in cases involving a limited number of victims, such as dominance or predatory pricing. Diverging from recent studies, the paper concludes that the superiority of the FNE is only partial, and thus the policy should aim at bringing together both mechanisms of enforcement. Private and public enforcement does not behave as structural substitutes but as strategic complements. Hence, strengthening one at the expense of the other is plainly a bad idea.
\end{abstract}

KEY WORDS: Antitrust - public enforcement - litigation

Sumario: Introducción. 1) Mecanismos de fiscalización: ¿Estado o mercado? 2) Una mirada a los litigios sobre libre competencia. 4) Evaluando la intensidad de la disputa. 5) El problema de la colusión. 6) Conclusiones.

Para entender cabalmente la mano invisible del mercado, debemos entender primero la mano visible de la burocracia ${ }^{1}$.

Williamson, Oliver (1985) The Economic Institutions of Capitalism: Firms, Markets, Relational Contracting. Nueva York: Free Press. 


\section{INTRODUCCIÓN}

El primer contacto que tuve con el Derecho de la Libre Competencia se produjo durante una audiencia en un juicio sobre colusión. Acababa de comenzar a trabajar como procurador, todavía no había tenido instrucción formal en esta área del Derecho, y nunca antes había entrado al Tribunal de la Libre Competencia (“TDLC”). Mi impresión, obviamente marcada por los aspectos visuales del rito, fue que la contienda parecía desigual. Mientras la Fiscalía Nacional Económica ("FNE”) actuaba por intermedio de dos abogados, uno con mayor experiencia y otro que oficiaba de asistente, cada una de las cuatro empresas demandadas estaba representada por un equipo de entre tres y cinco profesionales ${ }^{2}$. Ello contrastaba con lo que me había tocado observar en los litigios entre particulares, donde ambas partes parecían competir con igualdad de armas ${ }^{3}$.

En el marco de un sistema procesal acusatorio, esto es, uno donde el tribunal adopta un rol pasivo y toma conocimiento de los hechos a través de la actividad probatoria de las partes, el litigante con mayores recursos debiera tender a prevalecer ${ }^{4}$. En otras palabras, teniendo en cuenta que los antecedentes que presentan las partes constituyen el principal elemento de juicio del tribunal, y que sus contrapartes cuentan con un mayor

2 La FNE cuenta con cerca de 70 profesionales y dos de sus cuatro divisiones se relacionan directamente con litigios. Con todo, los problemas asociados a su menor disponibilidad de recursos es reconocida por la propia FNE. Ver, por ejemplo, Fiscalía Nacional Económica, Memoria Anual 2012, 10-11. Estas diferencias se repiten en muchos otros ámbitos del proceso. Así por ejemplo, de los doscientos informes presentados ante el TDLC desde entre los años 2004 y 2013, solamente 35 (18\%) fueron presentados por la FNE, mientras que $165(82 \%)$ corresponden a litigantes privados. Ver, Tribunal de la Libre Competencia, Listado de Informes Técnicos y Económicos 2013, Santiago: Inédito.

3 Esta es la situación que uno debiera esperar teniendo en cuenta los incentivos de las partes. En términos generales, los juicios funcionan con una lógica puramente redistributiva, esto es, como un juego de suma cero donde todo lo que gana el demandante sale del bolsillo del demandado. En ausencia de restricciones presupuestarias exógenas, esta simetría entre las ganancias de una parte y las pérdidas de la contraria debiera hacer que los esfuerzos desplegados por ambas sean también simétricos. Ver, Shavell, Steven. (1993) "The Optimal Structure of Law Enforcement". Journal of Law and Economics. $N^{\circ}$, pp. 255-287. 260-263; Garoupa, Nuno. (1997) “The Theory of Optimal Law Enforcement”. Journal of Economic Surveys, N¹1 Vol. 3, pp. 267-295. (1997b) 269-272; y Polinsky, Mitchell (2011) An Introduction to Law and Economics. Boston: Aspen Publishers, p. 75-83.

4 El sistema acusatorio es definido por oposición a uno inquisitivo, donde es el tribunal quien realiza esfuerzos proactivos por investigar los hechos de la causa. Para una discusión crítica sobre esta dicotomía, Damaska, Mirjan (2000) Las Caras de la Justicia y el Poder del Estado: Análisis Comparado del Proceso Legal. Santiago: Editorial Jurídica de Chile, p. 51 64. Los problemas del sistema acusatorio para lidiar con la asimetría de recursos entre las partes han sido extensamente estudiados, particularmente desde un ámbito de la sociología del Derecho que argumenta que los "ricos" tienden a prevalecer en este tipo de procesos. Ver, el estudio seminal de Galanter, Mark (1974) "Why The 'Haves' Come Out Ahead: Speculations on the Limits of Legal Change". Law \& Society Review, N9 Vol. 1, 95-160 pp., así como la extensa literatura subsecuente. 
número de recursos humanos y materiales para producir tales antecedentes, lo lógico sería que la FNE perdiera frecuentemente, o al menos con una mayor frecuencia relativa que los demandantes particulares. Para mi sorpresa, sin embargo, este organismo tiene reputación de ser un litigante tremendamente eficaz ${ }^{5}$.

Un estudio reciente de Aldo González y Alejandro Micco pareciera confirmarlo $^{6}$. Sobre la base de un análisis de las estadísticas de juicios ante el TDLC entre los ańos 2004 y 2013, los autores sostienen la probabilidad de que la FNE obtenga una sentencia favorable sería cerca de tres veces más alta que la de los demandantes privados. Dentro de las posibles explicaciones para esta superioridad de la FNE, se mencionan la mayor especialización y experiencia de sus equipos de trabajo, sus atribuciones para obtener medios de prueba mediante herramientas compulsivas, así como la tendencia de los litigantes privados a instrumentalizar el litigio con fines estratégicos ${ }^{7}$. En virtud de lo anterior, los autores recomiendan fortalecer la persecución pública y disminuir el protagonismo de los demandantes privados.

Desde una perspectiva forense, sin embargo, ninguna de las explicaciones anteriores resulta persuasiva. Tratándose de las supuestas ventajas de especialización, es difícil creer que un organismo público pueda sostener una ventaja de este tipo cuando buena parte de sus profesionales terminan emigrando al sector privado ${ }^{8}$. Al final del día, el éxito de las

5 Conforme a sus propias estimaciones, la tasa de éxito de la FNE sería cercana al 80\%. Ver, Fiscalía Nacional Económica. Memoria Anual 2012, Santiago: Inédito, p. 10. En contraste, más de un $70 \%$ de los juicios iniciados por demandantes privados terminan en abandono, archivo y otras situaciones donde ni siquiera llega a pronunciarse una sentencia definitiva. Ver, Tribunal de la Libre Competencia. Memoria Anual 2013. Santiago: Inédito, p. 17.

6 Existen dos estudios sucesivos de los mismos autores y cuyo contenido es similar. El primero de ellos se encuentra publicado en la revista Estudios Públicos y el segundo en la Journal of Competition, Law \& Economics. Para efectos de simplificar las referencias cruzadas, en lo sucesivo solamente se hará mención al último de ellos. Ver, GonzÁlez, Aldo, y Micco, Alejandro (2014) "Private versus public enforcement: Evidence from Chile". Journal of Competition Law and Economics, N¹0 Vol. 4; GonzÁlez, Aldo, Micco, Alejandro, y CaIcha, Constanza (2013). "El Impacto de la persecución pública en los juicios sobre libre competencia en Chile”. Estudios Públicos, N¹32, 39-69 pp.

7 Desde la célebre disputa entre Gary Becker y Richard Posner, es usual encontrar esta referencia a la instrumentalización del litigio por parte de demandantes privados. En términos generales, esta idea se refiriere a situaciones donde la demanda seguiría una finalidad diferente a obtener una sentencia favorable, como sería gatillar una negociación paralela, hostigar a la contraparte, y recibir otro tipo de concesiones. Ver, Becker, Gary, y Stigler, George (1974) "Law Enforcement, Malfeasance, and Compensation of Enforcers". Journal of Legal Studies, N³, pp. 1-18; Landes, William, y Posner, Richard. (1975) "The Private Enforcement of Law”. Journal of Legal Studies, N4, Vol 1.

8 Si uno revisa los antecedentes de las firmas de abogados que se especializan en libre competencia, un número importante de sus miembros trabajaron previamente en la FNE. Así por ejemplo, dentro de las firmas que ocupan los tres primeros lugares del último ranking de Chambers \& Partners, cerca de un $40 \%$ de los abogados especialistas en libre competencia tienen experiencia previa en el sector público. 
instituciones depende de la calidad de los profesionales que la componen. Respecto de las atribuciones especiales de investigación, ellas fueron incorporadas recién durante la reforma del 2009 y solamente para ilícitos relacionados con la colusión ${ }^{9}$. La incorporación de estas atribuciones ciertamente limita la fortaleza de las conclusiones hacia el futuro, pero difícilmente podría explicar el comportamiento de la FNE cuando solo una pequeña minoría de los casos estaba en condiciones de verse afectado por la reforma. Finalmente, es verdad que la efectividad promedio de los demandantes privados se contamina cuando existe una fracción importante que instrumentaliza el proceso ${ }^{10}$. Pero uno quisiera saber cómo se compara la FNE contra quienes efectivamente litigan, y no solamente contra aquellos para quien el litigio es simplemente un pretexto.

El primer objetivo de este trabajo es justamente satisfacer esta inquietud, analizando cómo varían las ventajas comparativas de la FNE a medida que la intensidad de la disputa aumenta. El razonamiento implícito es que los demandantes privados y la FNE tienen diferencias estratégicas que explican su comportamiento, siendo la matriz de incentivos subyacente lo que determina cuáles batallas deciden pelear y cuánto esfuerzo desplegar en cada disputa ${ }^{11}$. En concreto, la FNE funciona bajo una estructura burocrática que, en comparación a lo que sucede con los demandantes privados, presenta un problema de agencia significativamen-

9 Ambas circunstancias limitan la influencia de la reforma del 2009 en la muestra de casos utilizada por Aldo González y Alejandro Micco. Por un lado, su foco se refiere a sentencias que ocurren entre dos y tres años después de iniciado el caso, de modo que en más del $60 \%$ de los juicios bajo análisis la FNE carecía de estas atribuciones especiales de investigación. Por otro lado, las infracciones relacionadas con la colusión representan menos de un 15\% de los casos. Tomado ambas circunstancias conjuntamente, en cerca de un 5\% del total de casos la FNE estuvo en condiciones de poder utilizar estas nuevas atribuciones.

10 En cualquier tribunal es usual que la mayoría de los casos sean relativamente sencillos, mientras que solamente en unos pocos las partes estén dispuestas a intensificar la disputa. Ver, Priest, George, y Klein, Benjamin (1984) “The Selection of Disputes for Litigation”. The Journal of Legal Studies, $N^{\circ} 13$ Vol. 1, pp. 6-24. Tratándose de la justicia civil, por ejemplo, la gran mayoría de las causas corresponden a cobranzas de instituciones financieras. Más aún, incluso entre aquellos asuntos donde existe una controversia real entre las partes, cerca de un $80 \%$ terminan en una salida alternativa a la sentencia y solo en un $20 \%$ las partes perseveran en la disputa hasta el final, esto es, hasta conseguir una sentencia definitiva. Ver, Vargas, Juan, Peña, Carlos, y Correa, Jorge (2001) El Rol del Estado y el Mercado en la Justicia. Santiago de Chile: Universidad Diego Portales, pp. 103-115.

11 El concepto de estrategia es tomado aquí en su acepción técnica, conforme al uso desarrollado en la literatura sobre teoría de juegos. En este sentido, la idea de estrategia o hace referencia al desarrollo de un plan de acción que anticipa la conducta del adversario y ofrece una respuesta óptima para los fines de quién toma la decisión. Ver, por ejemplo, Osborne, Martin, y Rubinstein, Ariel (1994) A Course in Game Theory. Cambridge: MIT Press, pp. 103-104. Para una introducción a esta literatura desde la perspectiva del Derecho, ver Baird, Douglas, Gertner, Robert, y Picker, Randal (1998) Game Theory and the Law. Cambridge: Harvard University Press, p. 4-5. 
te diferente ${ }^{12}$. Mientras los privados tienen costos de agencia variables, que dependen del número de partes que resulte necesario coordinar, la FNE funciona con una estructura burocrática cuyos costos son más bien constantes. Ello hace que la FNE tenga ventajas comparativas en la persecución de ilícitos multilaterales, como la colusión, donde el daño está disperso entre una multitud de consumidores. En contraste, los privados tienen ventajas comparativas en casos que involucran ilícitos unilaterales, como sería el caso del abuso de posición dominante, donde el número de partes involucradas es reducido.

En suma, la FNE debiera exhibir un desempeño judicial más bien uniforme, en circunstancias que los demandantes privados tendrían tanto un techo más alto como un piso más bajo. La evidencia recogida en la base de datos del TDLC confirma estas intuiciones. Si consideramos la presencia de la FNE como una manera de dividir los perfiles de demandante entre público y privado, el número de audiencias puede utilizarse para medir la intensidad de la disputa. Bajo estos supuestos, los resultados reflejan que la FNE efectivamente litiga con mayor éxito que los demandantes privados en una gran parte de los casos donde el nivel de intensidad de la disputa es relativamente bajo. Sin embargo, en una pequeña fracción de casos donde el nivel de disputa es relativamente alto, son los demandantes privados quienes muestran un mejor desempeño. Por su parte, con relación al tipo de disputa perseguido, los privados muestran un nivel importante de especialización en ilícitos unilaterales, lo cual es consistente con la idea de que la estructura de sus costos de agencia le entregaría ventajas comparativas en este tipo de casos. Al contrario, la FNE no pareciera seguir un patrón de selección definido.

El segundo objetivo de este trabajo consiste en destacar las consecuencias de política pública que surgen a la luz de esta evidencia. El punto central es que las diferencias de comportamiento entre los demandantes privados y la FNE fortalecen el funcionamiento del sistema de fiscalización en su conjunto. Debido a que las ventajas comparativas de cada tipo de litigante se relacionan con las características subyacentes de los tipos de infracción, lo lógico sería fomentar la división de trabajo

12 El problema de agencia supone la interacción de dos partes: el agente y el principal. Se llama agente a quien tiene el poder para tomar decisiones sobre una esfera de interés; y principal, a quien soporta los riesgos derivados de las decisiones del agente. Más que un problema en particular, en todo caso, con esta denominación se hace referencia a la serie de costos que se producen a partir de la asimetría de información y la divergencia de intereses entre las partes. Un clásica formalización del problema de agencia, en Arrow, Keneth. (1985) “The Economics of Agency". En J. Pratt y R. Zeckhauser (Eds.), Principals and agents: The structure of business. Cambridge: Harvard Business Press, p. 1184-1195. Para una revisión de este tópico desde la perspectiva más amplia de las ciencias sociales, ver SHapiro, Susan (2005) "Agency Theory". Annual Review of Sociology, №31, 263-284 pp. 
y permitir que ambos mecanismos se complementen recíprocamente ${ }^{13}$. Antes que implementar un programa de sustitución, donde se fortalezca la FNE y se limite la intervención privada, resulta preferible continuar con la orientación adoptada por el actual Fiscal Nacional Económico y redireccionar los esfuerzos de persecución pública hacia la persecución de carteles. Como en la fábula de la liebre y la tortuga, conocer sus propias limitaciones es lo permite a la FNE ajustarse al peso de la burocracia y desarrollar una estrategia que potencie sus fortalezas.

El artículo de González y Micco es, obviamente, el trabajo más cercano y mi principal punto de referencia ${ }^{14}$. En términos metodológicos, la principal innovación de este artículo consiste en enriquecer el análisis estadístico por la vía de diferenciar entre los distintos niveles de intensidad de la disputa. Desde una perspectiva sustantiva, ello se justifica en que la estructura de los costos de agencia determinaría la intensidad con que cada tipo de litigante despliega su esfuerzo en juicio. A nivel de resultados, ello se traduce en las siguientes diferencias. Primero, en este trabajo se documenta que la superioridad de la FNE es relativa, limitándose respecto de aquellos juicios donde la intensidad de la disputa es menor. A ello se agrega que los privados tienen un sesgo hacia la persecución de ilícitos unilaterales, mientras que la FNE no muestra ningún patrón de selección determinado. Segundo, la referencia a los casos donde los privados instrumentalizan el juicio es engañosa. Efectivamente explica la superioridad de la FNE en promedio, pero oculta su inferioridad relativa en los casos más disputados. Tercero, el desempeño de la FNE en casos donde ella inició el juicio como consecuencia de una investigación en sede administrativa, es prácticamente igual que su desempeño en los casos donde se suma a una demanda presentada previamente por un particular. Si algo puede deducirse de esto último, es que las atribuciones de investigación de la FNE parecieran irrelevantes hasta antes de la reforma del 2009.

13 Aunque el presente trabajo se refiere a su desempeño como litigantes, la complementariedad entre agentes públicos y privados se manifiesta en otros ámbitos del sistema de fiscalización. Así por ejemplo, en un trabajo previo se muestra que la SVS ha desarrollado un sesgo de vigilancia propio de un sistema centralizado. De este modo, el fomento de la fiscalización privada -que responde a la lógica de un sistema descentralizado y resulta menos predecible-, permitiría mejorar la detección de infracciones y la fortaleza del sistema en su conjunto. Ver, Pardow, Diego (2012) "La Experiencia Chilena Disuadiendo Ilícitos Corporativos”. Derecho Público Iberoamericano, N¹ Vol. 1, pp. 55-85.

14 Además, Paredes, Ricardo (1995) "Jurisprudencia de las Comisiones Antimonopolios en Chile”. Revista Estudios Públicos, N58, pp. 227-320, ya había estudiado empíricamente el desempeño de la institucionalidad sobre libre competencia, aunque enfocado en el tribunal y bajo el antiguo esquema de comisiones, Por su parte, TARZIJÁn, Jorge, y Hevia, José (2005) "Jurisprudencia Sobre Precios Predatorios en Chile: ¿Han Sido Uniformes Los Criterios Aplicados?”. Revista ABANTE, N8 Vol. 2, pp. 59-85, también reunieron evidencia orientada a sistematizar los criterios con los que se decidieron los casos. 
En términos de la literatura comparada, este artículo se inserta dentro de los trabajos que comparan los mecanismos de fiscalización pública y privada ${ }^{15}$. Dentro del ámbito de la libre competencia, Estados Unidos y el Reino Unido han sostenido su tradicional compromiso con la litigación privada, mientras que la Comisión Europea comenzó fomentar reformas legales en esta dirección hace casi 10 años ${ }^{16}$. Esta tendencia hacia la privatización del sistema de fiscalización ha sido objeto de numerosas críticas, centradas principalmente en los problemas que genera la instrumentalización del litigio por parte de demandantes oportunistas ${ }^{17}$. En buena medida, sin embargo, dichas críticas se basan en una presunción benevolente respecto de la fiscalización pública y su capacidad para orientarse conforme al principio de maximización del bienestar social. Centrarse en los costos de agencia permite un mayor escepticismo respecto de la finalidad perseguida por los litigantes, y desde esta perspectiva, descansa en los supuestos que suele utilizar la literatura sobre organizaciones burocráticas ${ }^{18}$.

El resto del artículo está organizado de la siguiente manera. La segunda sección describe un marco conceptual que permite explicar las diferencias en el desempeño de los tipos de litigantes como una consecuencia de sus costos de agencia. Para efectos de facilitar la lectura, la formalización de un modelo analítico se desarrolla en el anexo. La tercera

15 Para una revisión de la literatura en este ámbito, ver Martini, Gianmaria, y Rovesti, Cinzia (2004) "Antitrust Policy and Price Collusion: Public Agencies vs. Delegation". Recherches Économiques de Louvain/Louvain Economic Review, Nº70, pp. 127-151

16 En Estados Unidos existen cerca de 10 veces más demandas privadas en materia de libre competencia que litigios iniciados por organismos públicos. Ver, Nafta Working Group, Private Actions for Violations of Antitrust Laws. Nueva York: Inédito, Appendix A. Con relación a la Comisión Europea, ver Green Paper on Damages Actions for Breach of the EC Antitrust Rules, COM (2005) 672. Una revisión del panorama comparado, en GinsBurg, Douglas (2005) "Comparing Antitrust Enforcement in the United States and Europe". Journal of Competition Law and Economics, N¹ Vol. 3, pp. 427-439; Trebilcock, Michael, y Roach, Kent (1996) "Private Enforcement of Competition Laws". Osgoode Hall Law Journal, N³4, pp.461; Wickelgren, Abraham (2012) "Issues in Antitrust Enforcement". En Einer Elhauge (Ed.), Research Handbook on the Economics of Antitrust Law. Nueva York: Edward Elgar Publishing.

17 Ver, por ejemplo, McAfee, Preston, Mialon, Hugo, y Mialon, Sue (2008) "Private v. Public Antitrust Enforcement: A Strategic Analysis". Journal of Public Economics, № 92 Vol. 10, pp. 1863-1875; Schwartz, Warren, y Wickelgren, Abraham (2011). "Optimal Antitrust Enforcement: Competitor Suits, Entry, and Post-entry Competition”. Journal of Public Economics, N95 Vol. 7, pp. 967-972.

18 En cierta medida, el razonamiento sigue el enfoque tradicional de Friedrich Hayek, donde la elección entre lo público y lo privado depende del costo de reunir la información necesaria. En casos donde los daños del ilícito se manifiestan en un patrimonio concreto, como sucede con el abuso de posición dominante, la propia víctima tiene acceso a la información a bajo costo y puede llevar adelante el caso privadamente. Al contrario, si la víctima es una noción difusa, como sucede con el ilícito de colusión y la clase general de consumidores afectados, los organismos públicos tendrían ventajas comparativas debido a su mayor capacidad para construir economías de escala. Ver, HAYEK, Friedrich (1945) "The use of knowledge in society". The American Economic Review, N³5 Vol. 4, pp. 519-530. 
sección describe la base de datos utilizada y las tendencias generales en los juicios sobre libre competencia. La cuarta sección discute la metodología con que se determina la intensidad de la disputa, explicando con mayor detención las diferencias de desempeño entre la FNE y los demandantes privados. La quinta sección analiza los patrones de selección de los litigantes, y en especial, las medidas de política pública que sugiere la evidencia revisada. La sexta y última sección resume las conclusiones.

\section{MECANISMOS DE FISCALIZACIÓN: ¿ESTADO O MERCADO?}

Una de las ideas más potentes desarrolladas por el análisis económico del derecho es que las sanciones máximas son óptimas. Ello descansa en un enfoque donde el objetivo de las sanciones es disuadir la comisión de ilícitos, y la disuasión depende de dos factores: la severidad nominal de la sanción y la probabilidad de que el castigo sea efectivamente impuesto. Aumentar la probabilidad del castigo supone actividades costosas, como mejorar los organismos de fiscalización o aumentar los recursos con que cuentan nuestros tribunales, mientras que aumentar la severidad nominal de las sanciones es relativamente barato. Por eso, para alcanzar un determinado nivel de disuasión siempre sería más eficiente aumentar al máximo la magnitud de una multa y ahorrar proporcionalmente en los costos asociados a los mecanismos de fiscalización ${ }^{19}$.

Ahora bien, existen muchas situaciones donde aumentar la severidad nominal de las sanciones resulta poco efectivo. La vida natural de una persona es algo esencialmente finito, así como también lo es el patrimonio de una empresa. Más aún, los estudios sobre el comportamiento muestran que la eficacia marginal de las sanciones tiende a ser decreciente, esto es, la disuasión que genera una unidad tributaria adicional de multa, o un año adicional de prisión, disminuye a medida que el nivel del castigo aumenta ${ }^{20}$. En estos casos, donde el margen intensivo de una sanción se encuentra agotado, la única alternativa viable para aumentar el nivel de disuasión es actuar sobre el margen extensivo del castigo. Ello supone tanto aumentar la frecuencia con que detectamos la comisión de

19 Este enfoque fue desarrollado originalmente por BECKER, Gary. (1968). "Crime and Punishment: An Economic Approach”. Journal of Political Economy, N76 Vol. 2, pp. 169-217, y Stigler, George (1970) “The Optimum Enforcement of Laws”. The Journal of Political Economy, N78 Vol. 3, pp. 526-536. Para una revisión de la extensa literatura sobre este tópico, ver Garoupa (1997b) 30.

20 Ver, por ejemplo, Bebchuk, Lucian, y Kaplow, Louis. (1993). "Optimal Sanctions and Differences in Individuals' Likelihood of Avoiding Detection”. International Review of Law and Economics, N¹3 Vol. 2, pp. 217-224; Polinsky, Mitchell, y Shavell, Steven. (1992). "Enforcement Costs and the Optimal Magnitude and Probability of Fines". Journal of Law and Economics, N³5 Vol. 1, pp. 133-148. 
ilícitos, como la probabilidad con que los responsables serán efectivamente castigados.

Existen dos estrategias diferentes para mejorar los mecanismos de fiscalización. Una alternativa obvia es trabajar por el lado de la oferta, fortaleciendo los recursos materiales y humanos de los organismos públicos de fiscalización. Otra alternativa es confiar en que el mercado provea de representación legal adecuada para las víctimas, incluso si ello requiere implementar programas de subsidio a la demanda. Cada alternativa tiene sus problemas ${ }^{21}$. Los organismos de fiscalización públicos cuentan con recursos insuficientes, información incompleta y sus funcionarios tienen pocos incentivos para hacer su trabajo. Por su parte, los demandantes privados están sujetos a problemas de acción colectiva, parasitismo y conductas oportunistas. En definitiva, confiar en la capacidad emprendedora del mercado legal obliga a desgastar el sistema judicial con un número desproporcionado de falsos positivos, mientras que dejar todo en manos de la burocracia tiende a incrementar la fracción de ilícitos que quedan impunes $^{22}$.

La manera tradicional de abordar este tópico consiste en revisar los costos que supone reunir la información relativa a la comisión de un ilícito. Cuando el ilícito es claro y el autor fácil de identificar, las fiscalización realizada por la propia víctima tendría una ventaja comparativa debido a que se encuentra más cerca de las fuentes de información. Desde esta perspectiva, los organismos públicos de fiscalización constituyen sistemas centralizados de toma de decisiones, donde transmitir la información acerca del caso resulta costoso, mientras que la fiscalización privada actúa como un sistema descentralizado con menores barreras transaccionales. Con todo, el mejor acceso a la información por parte de los mecanismos de fiscalización privados depende en buena medida del número de víctimas involucrado. A medida que el número de víctimas crece, recolectar información acerca de la comisión del ilícito se vuelve progresivamente más caro, la coordinación entre los distintos involucrados se hace más difícil y se multiplican conflictos de intereses ${ }^{23}$. De este modo, cuando el

21 Existe una antigua polémica en la literatura sobre análisis económico del derecho respecto de los problemas y ventajas de cada mecanismo. Para una aproximación a esta disputa desde la perspectiva de la libre competencia, ver Posner, Richard (1976) Antitrust Law: An Economic Perspective. Chicago: University of Chicago Press, p. 20.

22 Garoupa, Nuno (1997a) "A Note on Private Enforcement and Type-I Error". International Review of Law and Economics, $\mathrm{N}^{\circ} 17$ Vol. 3,pp. 428-429. En términos generales, el castigo de ilícitos lleva asociado dos tipos de errores diferentes: condenar a una persona por un ilícito que no cometió (falso positivo), y dejar sin castigo a una persona que efectivamente cometió un ilícito (falso negativo). Ver, Kaplow, Louis, y Shavell, Steven (1994) "Accuracy in the Determination of Liability". Journal of Law and Economics, $\mathrm{N}^{\circ} 37$ Vol. 1, pp. 1-15.

23 Estos problemas se encuentran extensamente documentados en el caso de las acciones de clase y otro tipo de litigación representativa. Ver, por ejemplo, MACEY, Jonathan, y MilleR, Geoffrey (1991) "The Plaintiffs' Attorney's Role in Class Action and Derivative Litigation: 
daño está disperso entre muchas víctimas, o la fiscalización requiere costos hundidos importantes, son los organismos públicos quienes tendrían la ventaja debido a su capacidad para capturar los beneficios asociados a la prevención general ${ }^{24}$.

A diferencia de trabajos recientes sobre fiscalización en el ámbito de la libre competencia, el enfoque desarrollado en este artículo se centra en el desempeño relativo de los litigantes ${ }^{25}$. Para ello, un primer paso en la construcción del argumento consiste en comprender que los juicios tienen una lógica estratégica. Tomando en cuenta el efecto de salidas alternativas, la probabilidad de obtener una sentencia favorable no depende tanto de las características intrínsecas del caso, sino más bien del esfuerzo que realizan los litigantes por convencer al tribunal ${ }^{26}$. Cuando se detecta una infracción pero la parte involucrada es claramente inocente, lo razonable es que cualquier mecanismo de fiscalización se abstenga de intervenir. Al contrario, cuando el involucrado es claramente culpable, las partes debieran ser capaces de llegar a un acuerdo. Los litigios representan una situación especial, donde las partes están dispuestas a incurrir en los costos que supone llevar adelante un juicio, únicamente si es que existe algo genuino que discutir ${ }^{27}$.

Economic Analysis and Recommendations for Reform”. University of Chicago Law Review, $\mathrm{N}^{\circ} 58$ Vol. 1. Para una aproximación desde el derecho de la libre competencia Breit, William, y Elzinga, Keneth (1974) "Antitrust enforcement and economic efficiency: The uneasy case for treble damages". Journal of Law \& Economics, N¹7 Vol. 329; SALOP, Steven, y White, Lawrence. (1985). "Economic Analysis of Private Antitrust Litigation". Georgetown Law Journal, N74, pp. 1001-1071; Smith, James, y Vaughan, Michael (1986) "Economic Welfare, Price and Profit: The Deterrent Effect of Alternative Antitrust Regimes". Economic Inquiry, N²4 Vol. 4, pp. 615-629.

24 En este contexto, la prevención general se refiere a la posibilidad de disuadir a muchos delincuentes potenciales con un mismo esfuerzo de fiscalización. Esto es lo que sucede con ciertos mecanismos de información que funcionan como monopolios naturales, como las bases de datos de huellas digitales o ADN, los sistemas de control de contribuyentes, y otros registros que típicamente llevan organismos públicos. Ver, Polinsky y Shavell (2000). Así por ejemplo, Segal, Ilya, y Winston, Michael (2006) "Public vs. Private Enforcement of Antitrust Law: A Survey". Stanford Law \& Economics Olin Working Paper, analizan la diferencia de objetivos entre los mecanismos de fiscalización pública y privada.

26 Debido a que las partes tienen información imperfecta acerca de las características del caso (v.g. situación factual, derecho aplicable, consideraciones políticas), los litigios responden a una dinámica en la cual ambas partes son mutuamente optimistas respecto de sus probabilidades de ganar. Ver, Cooter, Robert, y Rubinfeld, Daniel (1989) "Economic Analysis of Legal Disputes and Their Resolution”. Journal of Economic Literature, N²8, pp. 1070-1072.

En términos formales, los litigios son actividades puramente redistributivas. Cuando el tribunal otorga una indemnización de perjuicios, o bien acoge una pretensión punitiva de multa, el dinero sale del bolsillo del demandado y entra al bolsillo del demandante. Exceptuando el valor de las sentencias como bienes públicos, un litigio no genera riqueza, sino simplemente altera su distribución. Por ello, es usual aproximarse a este tópico con modelos de rentismo no cooperativo, similares a los que se usan para analizar el cabildeo político o los conflictos internacionales. Ver, por ejemplo, Tullock, Gordon (1980) "Efficient RentSeeking”. En James Buchanan, Robert Tollison, y Gordon Tullock (Eds.), Toward a Theory of the Rent-seeking Society. Texas: Texas A \& M University Press. 
Desde esta perspectiva, los litigios funcionan como un torneo donde las partes compiten por persuadir al tribunal mediante la producción de evidencia ${ }^{28}$. Es posible que el tribunal esté sesgado hacia alguna de las partes, como cuando en materia laboral se establecen presunciones prooperario, o en materia penal se exige acreditar un delito más allá de una duda razonable. También puede suceder que la capacidad de cada parte para producir evidencia sea asimétrica, típicamente mentir es más caro que decir la verdad, y muchas veces hay diferencias respecto del valor de lo que está en juego ${ }^{29}$. Finalmente, puede ser que alguna de las partes decida litigar por razones exógenas al juicio, como desgastar a su contraparte, forzar una negociación o enviar una señal frente a futuras infracciones. Lo importante es que el juicio tenga inicialmente un resultado incierto, y que las partes puedan inclinar la balanza en su favor haciendo esfuerzos por persuadir al tribunal.

Un segundo paso en la construcción del argumento consiste en considerar la estructura secuencial de los litigios. Los procesos judiciales toman tiempo y se desarrollan a través de etapas sucesivas, dando lugar a situaciones que siguen una dinámica de guerra de desgaste ${ }^{30}$. A medida que los informes periciales, declaraciones de testigos, escritos de discusión y otros documentos se acumulan en el expediente, el poder persuasivo de un esfuerzo adicional disminuye. Debido a que el costo de litigar debiera ser relativamente constante, esta estructura secuencial donde aportar evidencia tiene beneficios marginales decrecientes, supone que cada parte tiene un punto donde prefiere rendirse a seguir litigando. Así por ejemplo, cuando alguna de las partes tiene una ventaja inicial, ya sea porque su pretensión es más fácil de probar o porque le favorecen las presunciones legales subyacentes, su preferencia debiera ser que la sentencia se dicte lo antes posible. Por el contrario, cuando alguien comienza el juicio en relativa desventaja, la estrategia obvia es dilatar el juicio ${ }^{31}$.

28 Existe un volumen importante de literatura analítica sobre litigios que adopta este enfoque. Su principal ventaja dice relación con la capacidad de explicar la decisión del tribunal como algo endógeno, esto es, algo que depende de lo que hagan los litigantes durante el proceso. Ver, Hirshleifer, Jack, y Osborne, Evan (2001) “Truth, Effort, and the Legal Battle". Public Choice, N¹08 Vol. 1, pp. 169-195; TAlley, Eric (2012) "Law, Economics, and the Burden (s) of Proof". En J. Arlen (Ed.), Research Handbook on the Economics of Torts. Nueva York: Edward Elgar Publications.

29 Ver Emons, Winand, y Fluet, Claude (2011) Adversarial Versus Inquisitorial Testimony. Documento de trabajo. Descargado de http://escholarship.org/uc/item/446030wd.

30 En concreto, el modelo analítico que subyace a los argumentos presentados en este trabajo sigue la estructura de un juego de sincronización, esto es, uno donde la opción principal de la partes es decidir cuándo abandonar el juego. Ver, Fudenberg, Drew, y Tirole, Jean (1991) Game Theory. Cambridge: MIT Press.

31 Si miramos este fenómeno desde la práctica forense, una queja usual en los juicios que involucran a consumidores o trabajadores, es que muchas empresas tienen como estrategia dilatar el juicio. A diferencia del enfoque tradicional, que explica estas circunstancias a partir de restricciones presupuestarias exógenas, el enfoque secuencial propuesto en este trabajo 
Una vez que consideramos la estrategia y secuencialidad de los juicios, el desempeño relativo de los litigantes puede entenderse como una consecuencia de su capacidad para producir evidencia y argumentos que persuadan al tribunal. Esta capacidad, a su vez, depende del tipo de costos de agencia que enfrente cada mecanismo de fiscalización. En primer lugar, tenemos a las víctimas del ilícito, las asociaciones de consumidores, organizaciones de la sociedad civil y otros mecanismos privados de fiscalización. Ellos se caracterizan porque sus incentivos se relacionan con el recupero esperado del litigio y sus costos dependen principalmente del número de partes que se necesite coordinar ${ }^{32}$. Al contrario, los organismos públicos son mecanismos de fiscalización que persiguen una pluralidad de fines diferentes, pero cuentan con la capacidad legal para representar el interés general y la estructura institucional para realizar sus propias investigaciones $^{33}$.

Cuando dos competidores se coluden para subir los precios de un producto enfrentan dos potenciales fuentes de litigio: la FNE puede perseguir que se les imponga una multa administrativa; y, por otro lado, los consumidores afectados pueden reclamar perjuicios. Para efectos de ilustrar la distinción anterior, miremos las diferencias entre ambos mecanismos de fiscalización cuando empiezan y terminan un litigio. Tratándose de un abogado privado que busca demandar en representación de los consumidores, una de las dificultades iniciales que enfrenta consiste en obtener el consentimiento de cada uno de los afectados y coordinar cualquier posible diferencia entre ellos. En contraste, la FNE tiene legitimación activa por el solo ministerio de la ley y su estructura burocrática le permite aprovechar economías de escala en la recolección de información. De este modo, mientras los demandantes privados enfrentan costos de agencia que varían con el número de partes involucradas, para un organismo pú-

muestra que las estrategias dilatorias pueden ser consecuencia de las presunciones subyacentes. Ver, Bernardo, A., Talley, Eric, y Welch, Ivo (2000) "A Theory of Legal Presumptions". Journal of Law, Economics, and Organization, N 16 Vol. 1, pp. 30-35.

32 Alguien podría que resulta discutible tratar a estos mecanismos de fiscalización privados como "firmas" que maximizan la rentabilidad del litigio. Ciertamente existen entidades privadas que persiguen finalidades altruistas, pero al menos en términos empíricos, la principal fuente de litigación privada pareciera ser la figura de un abogado trabajando a recupero. Ver, Mery, Rafael (2006) Una Aproximación Teórica y Empirica a la Litigación Civil en Chile. Documento de trabajo. Santiago: Centro de Investigación y Desarrollo Empresaria, 22-26; García, José Francisco, y Leturia, Francisco José (2006) "Justicia Civil: Diagnóstico, evidencia empírica y lineamientos para una reforma”. Revista Chilena de Derecho, N³3 Vol. 2, pp. 348-351.

33 Esta pluralidad de fines es la crítica que suele hacerse a las organizaciones burocráticas, por cuanto dificulta establecer una relación entre esfuerzo y resultado. Ver, Rose-Ackerman, Susan (1986) "Reforming Public Bureaucracy through Economic Incentives?". Journal of Law, Economics and Organization, $\mathrm{N}^{\circ} 2$ Vol. 1, pp. 131-61, para un clásico estudio sobre la materia. 
blico dicha circunstancia resulta relativamente indiferente en términos de $\operatorname{costos}^{34}$.

En relación con la finalización de un juicio, cuando el tribunal decide un caso en favor de los consumidores el recupero correspondiente se les entrega directamente y el abogado típicamente puede retener un porcentaje a título de remuneración. Al contrario, en el caso de la FNE, las multas van a rentas generales de la nación, sin que ello influya en las remuneraciones de los funcionarios que llevaron adelante el caso. Ciertamente cualquier institución pública tiene incentivos reputacionales para esforzarse durante el litigio, y de hecho, un caso donde exista un mayor número de afectados puede resultarle más atractivo en términos de su impacto comunicacional. Sin embargo, los incentivos de los organismos públicos se relacionan con la diferencia discreta entre ganar y perder, antes que con la magnitud continua del recupero.

Como se aprecia, el esfuerzo de los mecanismos de fiscalización privados puede concebirse como una función dependiente de dos factores: la magnitud del recupero y el número de víctimas involucradas. En contraste, los mecanismos de fiscalización pública parecen responder a dichas variables pero solo de manera imperfecta ${ }^{35}$. En este contexto, cada mecanismo de fiscalización tendría sus propias ventajas dependiendo del tipo de ilícito involucrado. Por ejemplo, el abuso de posición dominante o la utilización de precios predatorios son infracciones que involucran a un número limitado de partes, al punto que la víctima y el autor usualmente comparte un mercado donde el número de competidores es limitado ${ }^{36}$. Al contrario, tratándose de ilícitos como la colusión de precios, tanto el daño como la información relevante acerca del caso se encuentran dispersos entre gran número de víctimas. Ello implica que los costos de agencia asociados a coordinar a las víctimas en una infracción de este tipo debie-

34 Para una discusión más extensa acerca de la diferencia entre los costos relacionados con agregar múltiples principales, y aquellos que responden a las deficiencias inherentes al proceso de toma de decisiones del agente, ver Williamson (1985) 90-102.

35 En la terminología tradicional de Michael Jensen y William Meckling, los costos de agencia de los mecanismos privados responderían a la lógica de gastos de "monitoreo por parte del principal" y de "coordinación por parte del agente". Por su parte, los costos de agencia de los mecanismos públicos encajarían en la categoría de "pérdida residual". Ver, Jensen, Michael, y Meckling, William (1976) "Theory of the firm: Managerial behavior, agency costs and ownership structure". Journal of Financial Economics, N³ Vol. 4, pp. 308-310.

36 Ciertamente podría objetarse que la víctima final de cualquier conducta contraria a la competencia es, por definición, la generalidad de los consumidores. Con todo, el concepto de víctima es utilizado aquí en un sentido procesal, como la persona legitimada para exigir judicialmente una indemnización de perjuicios o sanción administrativa. Respecto de la relación entre las nociones de víctima y consumidor en el derecho de la libre competencia, ver Cseres, Katalin (2005) Competition Law and Consumer Protection. Londres: Kluwer Law International. 
ran ser significativos. En definitiva, la estructura de costos de cada mecanismo de fiscalización sugiere que los organismos públicos tienen ventajas comparativas para perseguir ilícitos como la colusión, mientras que los demandantes privados estarían en una mejor posición relativa para perseguir conductas relacionadas con la dominancia o la predación.

\section{UNA MIRADA A LOS LITIGIOS SOBRE LIBRE COMPETENCIA}

Como en todo estudio cuantitativo, la elección de los métodos de análisis está limitada por la evidencia disponible. En este caso, la evidencia disponible consiste en la base de datos del TDLC, donde se agrupan 141 demandas, 42 requerimientos y 8 recursos de reclamación, correspondientes a la totalidad de las causas contenciosas iniciadas entre los años 1997 y 201337. Estas 191 observaciones se encuentran desagregadas a nivel de causa, esto es, existe una observación para cada litigio llevado ante el TDLC, pero no para cada una de las partes involucradas en ese litigio.

Pese a lo anterior, las variables relacionadas con la forma de iniciar el juicio permiten distinguir el grado de intervención de la FNE, y así agrupar las causas en las siguientes tres categorías: (i) Público, cuando el litigio se inició por parte de la FNE a través de un requerimiento; (ii) Mixto, cuando la FNE se hizo parte en una demanda privada; y, (iii) Privado, cuando estuvieron involucrados únicamente litigantes particulares. Distinguir entre litigios públicos y privados se justifica en virtud del objeto principal de este trabajo, porque permite evaluar el desempeño de la FNE respecto de los litigantes particulares. Por su parte, diferenciar entre litigios públicos y mixtos, permite evaluar si el hecho de haber realizado una investigación formal previa produce algún efecto en el desempeño relativo de la FNE ${ }^{38}$.

La Tabla $N^{\circ} 1$ resume la frecuencia de causas, agrupadas por tipo de litigio y forma de terminación. Como se aprecia, los litigios privados, esto es, las causas iniciadas por una demanda particular y donde la FNE se abstuvo de actuar como parte, constituyen con distancia el tipo de litigio

\footnotetext{
37 La base de datos utilizada en este estudio fue construida a partir de la base de datos del TDLC.

38 En términos generales, previo a presentar un requerimiento la FNE realiza una investigación formal sobre los hechos, donde recopila antecedentes y suele recibir información de los potenciales requeridos. En contraste, este procedimiento no es necesario cuando la FNE decide hacerse parte en una demanda privada. Para una explicación sobre el proceso de toma de decisiones de la FNE, ver VAldés, Domingo (2006) Libre Competencia y Monopolio. Santiago: Editorial Jurídica, pp. 542-545.
} 
más frecuente con más de un 70\%. Con todo, también constituyen el tipo de litigio donde es más común encontrar una forma de terminación previa a la sentencia: algo menos de la mitad de las demandas entre particulares terminaron mediante archivo, conciliación o desistimiento ${ }^{39}$. Por otra parte, una proporción similar de juicios concluyeron rechazando la demanda, y solamente en una veintena de causas, el demandante obtuvo una sentencia de condena.

\section{Tabla 1: TABla DE Frecuencia Litigios ante el TDLC (Tipo de Litigio y Forma de Terminación)}

\begin{tabular}{llll|l}
\hline \hline & $\begin{array}{l}\text { Público } \\
\text { № (\%) }\end{array}$ & $\begin{array}{l}\text { Mixto } \\
\text { oo (\%) }\end{array}$ & $\begin{array}{l}\text { Privado } \\
\text { No (\%) }\end{array}$ & TotAL \\
\hline Archivo & $1(0,5 \%)$ & $1(0,5 \%)$ & $32(16,8 \%)$ & $34(17,8 \%)$ \\
Conciliación & $4(2,1 \%)$ & $2(1 \%)$ & $16(8,4 \%)$ & $22(11,5 \%)$ \\
Desistimiento & - & - & $10(5,2 \%)$ & $10(5,2 \%)$ \\
Absolución & $16(8,4 \%)$ & $4(2,1 \%)$ & $60(31,4 \%)$ & $80(41,8 \%)$ \\
Absuelve \&3 No recurso & $7(3,6 \%)$ & $2(1 \%)$ & $31(16,2 \%)$ & $40(20,9 \%)$ \\
Absuelve \&3 CS Confirma & $7(3,6 \%)$ & $1(0,5 \%)$ & $24(12,5 \%)$ & $32(16,7 \%)$ \\
Condena \&3 CS Revoca & $3(1,5 \%)$ & $1(0,5 \%)$ & $4(2 \%)$ & $8(4,1 \%)$ \\
Condena & $22(11,5 \%)$ & $5(2,6 \%)$ & $18(9,4 \%)$ & $45(23,5 \%)$ \\
Condena \& No recurso & $8(4,2 \%)$ & $2(1 \%)$ & $9(4,7 \%)$ & $19(9,9 \%)$ \\
Condena \& CS Confirma & $13(6,8 \%)$ & $3(1,5 \%)$ & $8(4,2 \%)$ & $24(12,6 \%)$ \\
Absuelve \&3 CS Revoca & $1(0,5 \%)$ & - & $1(0,5 \%)$ & $2(1 \%)$ \\
\hline TotAL & $43(22,5 \%)$ & $12(6,3 \%)$ & $136(71,2 \%)$ & $191(100 \%)$ \\
\hline \hline
\end{tabular}

Nota: Tratándose de litigios terminados por sentencia definitiva, la frecuencia se muestra también desagregada, conforme a las posibles variaciones en el resultado del juicio durante su tramitación ante la Corte $\mathrm{Su}$ prema ("CS"). Los datos fueron obtenidos de la base de datos del TDLC, disponible en www.tdlc.cl

En contraste, los litigios iniciados mediante un requerimiento de la FNE constituyen menos de un $25 \%$ del total. Sin embargo, produjeron un número ligeramente superior de condenas que los litigios privados. Más aún, en términos relativos la FNE resultó vencedora en un mayor número de oportunidades de las que resultó vencida, y solamente en cinco oportunidades una causa iniciada por esta vía terminó mediante una salida alternativa a la sentencia. Aunque esta tendencia es discutida con

39 En contraste, bajo el antiguo régimen de comisiones, casi un $90 \%$ de las causas terminaron mediante sentencia, Paredes (1995) 235. La mitad de salidas alternativas a la sentencia, sin embargo, parece modesta en comparación con los estándares generales de la justicia civil. Conforme a García y Leturia (2006) 354, menos de un 9\% de las causas civiles terminaron por sentencia definitiva y cerca de un $66 \%$ terminaron por archivo. 
mayor detención en la sección siguiente, cabe destacar su coincidencia con las intuiciones desarrolladas previamente, y en concreto, con la idea de que la naturaleza variable de los costos de agencia de los demandantes privados los hace más proclives a litigar casos con pocas probabilidades de éxito ${ }^{40}$. Por último, el grupo de litigios mixtos constituye una clara minoría, distribuida equitativamente entre absoluciones y condenas.

A la luz de estos antecedentes, pareciera que la FNE es un mejor litigante que los demandantes privados, toda vez que consigue ganar en aproximadamente la mitad de los casos, tanto cuando comienza el litigio vía requerimiento como cuando se hace parte en una demanda particular ${ }^{41}$. Por su parte, los demandantes privados solamente obtienen una victoria en menos de un $15 \%$ de los casos en que participan. En otras palabras, por cada juicio ganado por un demandante privado, tres terminan en una salida alternativa y tres con un fallo adverso a sus intereses.

\section{TABLA 2: INTENSIDAD Y DURACión DE LOS LiTigios ANTE EL TDLC (Tipo de Litigio, Duración, $\mathrm{N}^{\circ}$ de Audiencias y Multas)}

\begin{tabular}{cllll}
\hline \hline & $\begin{array}{l}\text { Público } \\
\text { (39 obs.) }\end{array}$ & $\begin{array}{l}\text { Mixto } \\
\text { (9 obs.) }\end{array}$ & $\begin{array}{l}\text { Privado } \\
\text { (119 obs.) }\end{array}$ & $\begin{array}{l}\text { TOTAL } \\
\text { (167 obs.) }\end{array}$ \\
\hline Duración en Días & 581,49 & 660,17 & 408,34 & 463,14 \\
Mediana & 518 & 650,5 & 360 & 404 \\
No de Audiencias & 14,91 & 7,25 & 3,68 & 6,43 \\
Mediana & 11 & 2 & 0 & 0 \\
Multa TDLC en UTM & $10.306,33$ & 3.900 & $2.054,99$ & $4.854,83$ \\
Mediana & 660 & 600 & 0 & 0 \\
Multa CS en UTM & $10.586,11$ & $2.145,33$ & $1.962,45$ & $4.364,03$ \\
Mediana & 85.5 & 1000 & 0 & 0 \\
\hline \hline
\end{tabular}

Nota: Para cada variable, la línea superior indica el valor promedio o media aritmética, mientras que la línea inferior indica la mediana. Los datos fueron obtenidos de la base de datos del TDLC, disponible en www.tdlc.cl

40 Ello supone que las salidas alternativas a la sentencia constituyen un grupo de causas que, en razón de la configuración subyacente de los hechos, tendrían menores probabilidades de éxito. Con todo, la mayor parte de los estudios empíricos sobre la justicia en Chile coinciden en este punto.

41 Esta tendencia pareciera haberse acentuado durante los últimos años. Conforme a las estimaciones de la propia FNE, que se basan en resultados anuales y no en el promedio acumulado que muestra la tabla anterior, su tasa de éxito bajo la actual administración sería cercana al 80\% (Fiscalía Nacional Económica, Memoria Anual 2012. Santiago: Inédito, p. 10). 
No obstante, podría objetarse que mientras los litigios donde participa la FNE constituyen un grupo más uniforme, donde existen una serie de controles administrativos que aseguran un estándar mínimo de seriedad, el grupo de litigios privados está formado por demandas de todo tipo. Siguiendo con las ideas expuestas en la sección anterior, podría objetarse que el grupo de litigios privados incluye una proporción relativamente más alta de casos donde la intensidad de la disputa es relativamente baja. Ello correspondería a reclamos con poca probabilidad de éxito, donde el demandante está dispuesto a invertir un mínimo de recursos con el objetivo de probar la determinación del demandado, concitar la atención de los medios de prensa o forzar una negociación paralela. Desde esta perspectiva, la comparación de frecuencias únicamente permitiría sostener que la FNE litiga mejor que la media de un demandante particular, pero nada dice respecto de su desempeño en casos donde la intensidad de la disputa es comparable. Dicho de otro modo, una cosa es comparar a la FNE contra la caricatura del abogado picapleitos que instrumentaliza el juicio; y otra muy distinta, es medir el desempeńo de este organismo respecto de los mejores abogados de la plaza.

\section{Figura 1: Distribución de las Multas}

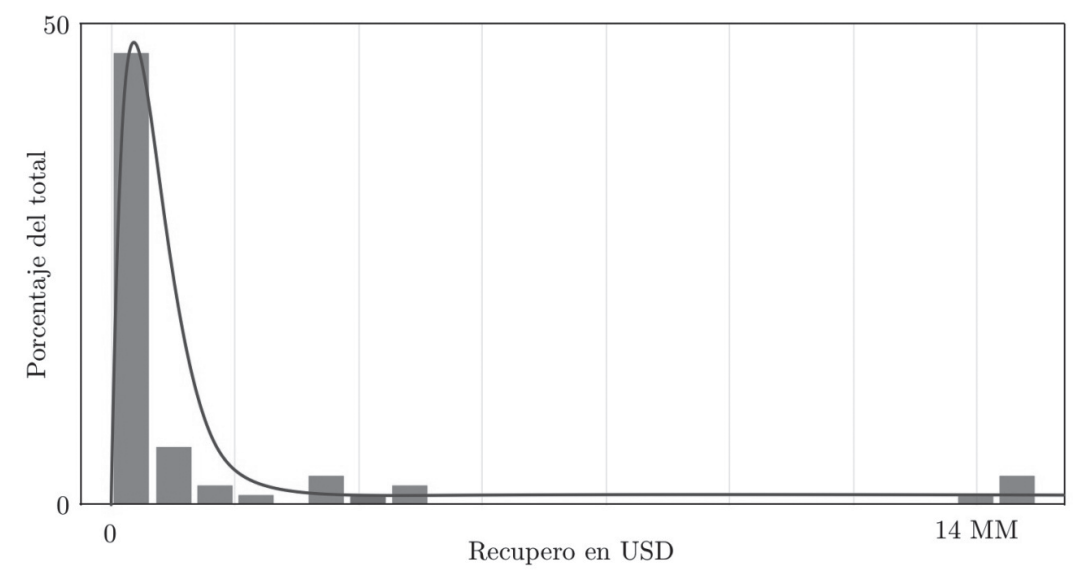

Nota: La figura muestra que la distribución empírica del recupero está sesgada hacia la derecha, siguiendo la forma de una distribución lognormal. Los rectángulos morados representan la distribución del recupero, mientras que la línea marrón representa una distribución log-normal para una escala comparable.

La Tabla 2 profundiza esta idea. Los litigios públicos no solamente producen un promedio de multas significativamente más alto que los litigios privados, sino que involucran un mayor número de audiencias de prueba y toman más tiempo. Estas últimas dos cantidades resultan particularmente 
expresivas. Mientras en los juicios iniciados por requerimiento los valores promedio y mediano son similares, tratándose de demandas entre particulares la diferencia entre ambas unidades de medida sugiere una distribución asimétrica. En otras palabras, en los litigios privados existe un grupo importante de causas donde el demandante no realizó mayores esfuerzos por obtener una victoria, lo que estaría reflejado en una duración promedio relativamente más baja y en un número mediano de audiencias igual a cero ${ }^{42}$.

El objetivo del análisis que sigue es desarrollar las herramientas necesarias para evaluar la intensidad de la disputa. Con este objetivo, se utilizará la variable que consigna el número de audiencias como una aproximación al esfuerzo desplegado por las partes, y consecuentemente, a la intensidad del juicio ${ }^{43}$. La hipótesis de trabajo, nuevamente, es que los organismos públicos enfrentan una estructura particular de costos de agencia diferente, y ello hace que su comportamiento estratégico en equilibrio se sistemáticamente diferente.

\section{EVALUANDO LA INTENSIDAD DE LA DISPUTA}

Las dos principales alternativas para realizar el análisis propuesto serían trabajar con un modelo de regresión lineal que utilice la magnitud de la multa como variable explicativa; o bien, con un modelo de regresión logística que utilice la probabilidad de condena como variable de respues$\mathrm{ta}^{44}$. Existen tanto razones metodológicas como sustantivas para preferir

42 En efecto, en 72 litigios privados no se realizó audiencia de prueba alguna. De ellos, 26 corresponden a causas terminadas en archivo, 25 a absoluciones y 8 a desistimientos. En contraste, 10 requerimientos de la FNE terminaron sin audiencias de prueba, pero la mayoría de ellas corresponde a conciliaciones, o bien a condenas pronunciadas frente a una parte relativamente pasiva.

43 Atendido que el procedimiento ante el TDLC es fundamentalmente escrito, podría objetarse que es la prueba documental, y no el número de audiencias, lo que mostraría el nivel de esfuerzo desplegado por las partes. Aunque el uso del número de audiencias se funda en razones prácticas, ya que la base de datos del TDLC carece de información acerca de la prueba documental rendida, esta objeción no pareciera ser problemática. Utilizando una muestra aleatoria de 10 casos, se registro el número total de fojas en el expediente como una manera de medir el volumen total de prueba. La correlación entre ambas variables fue de 0.93 , con un valor p de $0.01 \%$ para la hipótesis nula de que dicha correlación es cero. Del mismo modo, la correlación entre la duración del juicio y el número de audiencias, sugiere que el tiempo utilizado en la disputa es también es un indicador razonable de su intensidad, aunque menos certero. En este caso, la correlación entre ambas variables fue de 0.64 , con un valor p del 4,4\% para la hipótesis nula de que dicha correlación es cero.

44 Cox, James, y Thomas, Randall (2004) "Public and Private Enforcement of the Securities Laws: Have Things Changed Since ENRON”. Notre Dame Law Review, N80, p. 895, quienes realizan un análisis similar al aquí propuesto respecto de los litigios en el mercado de valores de Estados Unidos. En términos generales, la regresión es una herramienta que permite medir cuán significativa es la relación entre una variable de respuesta $(y)$ y una o más variables explicativas $\left(x_{i}\right)$, aislando aquella parte que obedecería simplemente a variaciones aleatorias. 
este último enfoque. Por una parte, debido a la manera en que está construida la base de datos del TDLC, los supuestos bajo los que funciona un modelo de regresión logística parecen más apropiados que los de un modelo de regresión lineal ${ }^{45}$. Por otra, según se detalla más abajo, cuando se utilizan funciones logísticas las unidades de medida resultan mucho más intuitivas a la hora de comparar el desempeño de los litigantes ${ }^{46}$.

El primer paso para definir este tipo de modelo de análisis es formalizar la variable de respuesta. Para estos efectos, la variable dependiente es la frecuencia con que "al menos uno" de los demandados recibe "alguna forma” de sanción ${ }^{47}$. La definición en términos binarios tiene sus ventajas, ya que de este modo únicamente necesitamos asumir que la probabilidad de condena para cada caso es condicionalmente independiente ${ }^{48}$. El segundo paso consiste en seleccionar las variables explicativas. Atendido que nuestra hipótesis de trabajo se centra en comparar los esfuerzos de los agentes públicos y privados durante el juicio, vamos a utilizar el tipo de litigio $\left(x_{1}\right)$ y el número de audiencias de prueba $\left(x_{2}\right)^{49}$. Siguiendo este procedimiento, la probabilidad de condena queda asociada a una función

45 Como los datos están desagregados a nivel de causa, lo que se registra es la suma de todas multas impuestas, sin que pueda determinarse cuantas personas fueron sancionadas. Así, trabajar sobre la magnitud de las multas implicaría forzar una relación lineal entre un juicio con un solo sancionado y un juicio con múltiples sancionados. Sin duda, el último caso podría tener una multa total más alta, pero resulta difícil saber si ello obedece la relación propuesta por el modelo o simplemente a la existencia de un mayor número de sancionados. En definitiva, cuando se utiliza la suma de las multas como variable de respuesta, sin tener el número de sancionados como variable explicativa, el supuesto de función lineal implícito en la regresión es problemático.

46 Ciertamente, podría usarse una función probit como lo hacen GonzÁlez y Micco (2014), y muchos otros estudios que trabajan con variables binarias. Aunque ambos enfoques entregan resultados prácticamente idénticos, se prefiere la regresión logística debido a su mayor cercanía respecto de los supuestos del modelo desarrollado en el Anexo.

47 Nuevamente, la desagregación a nivel de causa exige tomar en cuenta la manera en que se registran los datos. Tratándose de las sentencias, el fallo es registrado como condenatorio cuando al menos un demandado es sancionado y como absolutorio cuando se rechaza la totalidad de la pretensión respecto de todos los demandados.

48 La independencia condicional se refiere a que, más allá de la relación que se captura con las variables explicativas, el hecho de conocer el resultado de un caso en particular no ofrece ninguna información adicional acerca del resultado en los restantes casos. Ver, PAREdes (1995) 236, para una revisión de este supuesto en el marco de la jurisprudencia de la antiguas comisiones antimonopolios.

49 Alguien podría objetar que incluir otras variables explicativas podría mejorar la especificación de la regresión. En particular, la base de datos del TDLC permite determinar la duración del juicio (x3), mientras que existen variables categoriales que identifican el tipo de ilícito cometido (x4) y el mercado donde participaban los demandados (x5). Aunque intuitivamente estas circunstancias parecen relevantes, incluirlas solamente hubiera aumentado la varianza de los coeficientes. Usando un Test de Verosimilitud, comprobé la probabilidad de que estos coeficientes alternativos tuvieran un valor igual a cero, esto es, $\mathrm{H} 0: \mathrm{xi}=0$, para $\mathrm{i}$ $=3,4,5$. Los valores $\mathrm{p}$ en cada caso estuvieron lejos de ser significativos, con $\lambda 3=-10,65$, $\lambda 4=-3,29$ y $\lambda 5=-8,71$. Desde una perspectiva sustantiva, además, únicamente el tipo de ilícito resulta relevante para el enfoque de agencia propuesto y ello es objeto de un análisis separado en la sección siguiente. 
logística y el modelo queda plenamente identificado. La Tabla 3 muestra los resultados obtenidos. Todos los coeficientes son significativos de acuerdo con los niveles convencionales, lo que permite descartar que la relación propuesta obedezca simplemente a variaciones aleatorias. En otras palabras, los resultados prueban que existe una relación sistemática entre el tipo de litigante, el esfuerzo desplegado y la probabilidad de condena. Enseguida, el coeficiente marginal para los litigios privados tiene signo negativo, mientras que para los litigios públicos y mixtos tiene signo positivo. Los tres coeficientes, además, tienen un orden de magnitud similar. Ello implica que un demandado tendría una probabilidad sustancialmente más alta de ser condenado cuando litiga contra la FNE que cuando litiga contra un demandante privado.

Con relación al coeficiente de los litigios mixtos, el hecho de que su signo y magnitud sean similares al de los litigios públicos, muestra que la FNE es igualmente efectiva cuando presenta un requerimiento que cuando se adhiere a una demanda privada. La menor significancia de los coeficientes relativos a los litigios públicos no resulta sorpresiva, ya que constituye un subconjunto de datos relativamente pequeńo. No obstante, en lo sucesivo la comparación se centra en los litigios públicos y privados, considerando los litigios mixtos como parte de los primeros.

\section{TABla 3: COEFICIENTES DE LA RegResión LOGística (Resultado del Juicio, Tipo de Litigio y № de Audiencias)}

\begin{tabular}{|c|c|c|c|c|}
\hline Variable & Coef. & Error & Valor- $z$ & $\operatorname{Pr}(>|z|)$ \\
\hline $\begin{array}{l}\text { Litigio Privado }\left(x_{1}=0\right) \\
\qquad N^{o} \text { de Audiencias }\left(x_{1}=0: x_{2}\right)\end{array}$ & $\begin{array}{l}-2,369 \\
0,117\end{array}$ & $\begin{array}{l}0,338 \\
0,034\end{array}$ & $\begin{array}{l}-6,992 \\
3,429\end{array}$ & $\begin{array}{l}2,72 e-12^{* * *} \\
0,0006^{* * *}\end{array}$ \\
\hline $\begin{array}{l}\text { Litigio Mixto }\left(x_{1}=1\right) \\
\& N^{o} \text { de Audiencias }\left(x_{1}=1: x_{2}\right)\end{array}$ & $\begin{array}{l}2,324 \\
-0,111\end{array}$ & $\begin{array}{l}0,760 \\
0,060\end{array}$ & $\begin{array}{r}3,054 \\
-1,839\end{array}$ & $\begin{array}{l}0,002^{* *} \\
0,065\end{array}$ \\
\hline $\begin{array}{l}\text { Litigio Público }\left(x_{1}=2\right) \\
\& N^{o} \text { de Audiencias }\left(x_{1}=2: x_{2}\right)\end{array}$ & $\begin{array}{l}2,222 \\
-0,091\end{array}$ & $\begin{array}{l}0,546 \\
0,040\end{array}$ & $\begin{array}{l}4,069 \\
-2,236\end{array}$ & $\begin{array}{l}4,73 e-05^{* * *} \\
0,025^{*}\end{array}$ \\
\hline Niveles de significación: $0 \%$ ( $* * *$, & $y_{0}(* *)$, & (*), $5 \%$ & " у $10 \%$ ، & \\
\hline
\end{tabular}

Nota: La variable dependiente es el resultado del juicio, mientras que las variables independientes son el tipo de litigio y el número de audiencias. Para cada tipo de litigio, la línea superior indica el coeficiente marginal y la línea inferior el coeficiente de interacción con el número de audiencias.

No obstante, tratándose de la interacción con el número de audiencias el signo de los coeficientes se revierte, siendo negativo respecto de los litigios públicos y mixtos, pero positivo respecto de los privados. Al igual que en el caso anterior, el orden de magnitud de todos ellos es similar. Esta diferencia resulta particularmente interesante, ya que muestra que la 
mayor efectividad relativa de la FNE disminuye a medida que la disputa se hace más intensa. Al contrario, los demandantes privados parecieran volverse más eficaces cuando el esfuerzo probatorio de las partes aumenta. En términos generales, los resultados son consistentes con nuestra hipótesis de trabajo y el comportamiento esperable a la luz de los costos de agencia. Mientras estos pondrían a la FNE en una situación de desventaja relativa respecto de juicios donde las partes pelean más fieramente, también permitirían explicar su mejor desempeño en juicios de baja intensidad.

El contraste entre uniformidad y heterogeneidad es mostrado con mayor claridad en la Figura 2. La FNE tiene un mayor valor que los privados para la ordenada en el origen y un menor valor para la pendiente. Al contrario, para los demandantes privados la ordenada en el origen es más baja y la pendiente más alta. La mayor uniformidad de los litigios públicos es representada por una línea recta que oscila entre un 45\% y un $80 \%$ de tasa de éxito. En contraste, la heterogeneidad de los litigios privados es capturada a través de una línea curva, cuyo recorrido abarca íntegramente el rango de la probabilidad de condena.

\section{Figura 2: El DESEMPEÑo RELATIVO DE LA FNE ( $\mathrm{N}^{\circ}$ de Audiencias y Probabilidad de Condena)}

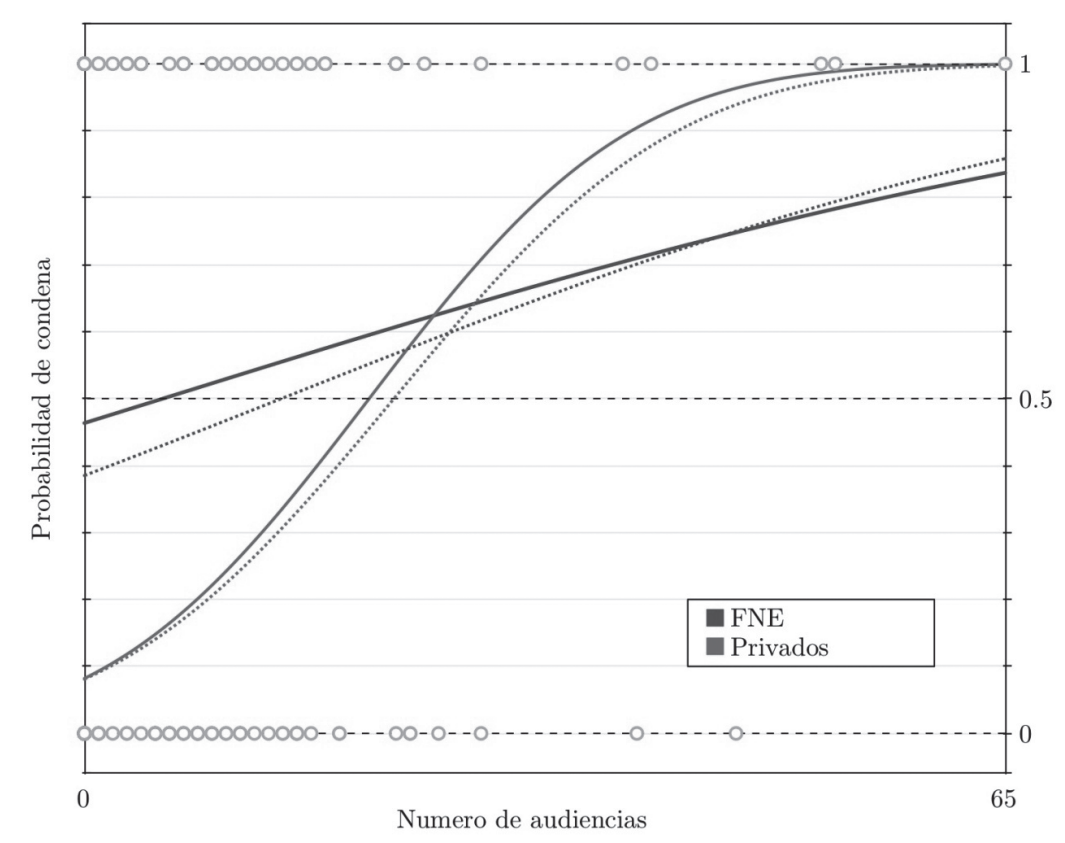

Nota: Las líneas marrones corresponden a litigios públicos y las violetas a privados. Por su parte, las líneas sólidas representan la probabilidad de condena ante el TDLC, mientras las líneas sementadas representan los valores obtenidos cuando se incluyen los resultados ante la 
CS. Los puntos anaranjados representan los casos incluidos en la base de datos del TDLC.

Un segundo aspecto a considerar dice relación con que la figura pareciera dividirse horizontalmente en dos mitades. En la mitad de la izquierda, donde se agrupan los casos menos disputados, la FNE se muestra claramente superior a los demandantes privados. De acuerdo con las ideas que se vienen exponiendo, ello obedecería a que la FNE cuenta con una mayor credibilidad que los demandantes privados frente al TDLC. A su vez, la justificación de esta mayor credibilidad se encontraría en que la FNE impulsa la mayor parte de sus juicios hasta el final y rara vez instrumentaliza el proceso por razones estratégicas. Con todo, la superioridad relativa de la FNE disminuye a medida que la actividad probatoria de las partes se intensifica.

A partir del punto de intersección de ambas líneas, la probabilidad de condena en los litigios privados se vuelve crecientemente más alta, sugiriendo que los demandantes particulares son más efectivos frente a casos donde la intensidad de la disputa es mayor. En este caso, la razón que explicaría está tendencia se relaciona con que los privados enfrentan menores costos de agencia. Por tanto, su mejor capacidad para capturar el flujo de caja positivo que supone el recupero, les entregaría una mayor disponibilidad de recursos para financiar la contratación de abogados, la producción de evidencia, y en general, la realización de esfuerzos destinados a prevalecer en el juicio. Por último, resulta interesante que los demandantes privados puedan remontar la ventaja de la FNE mediante incrementos en los esfuerzos para rendir prueba, ya que ello resulta consistente con la idea de que la reputación opera como un sesgo subjetivo del tribunal, cuya fuerza inicial se diluye a la luz del mayor número de antecedentes objetivos disponibles.

En cualquier caso, la distribución de los casos exige tomar los resultados con prudencia. La mitad de la izquierda tiene un número mayor de causas que la mitad izquierda, por lo que existe mucha más evidencia para demostrar el mejor desempeño de la FNE en casos menos disputados, que para hacer lo propio con la superioridad privada en el segmento de mayor disputa. Cabe mencionar también que los resultados se sostienen cuando se toma en cuenta el efecto de los recursos ante la Corte Supre$\mathrm{ma}^{50}$. Aunque las líneas segmentadas en la figura muestran una tendencia convergente, ello se explica porque las sentencias revocatorias de la Corte

50 Dentro de los litigios terminados antes de 2012, la FNE obtuvo un fallo favorable ante la Corte Suprema en un $57 \%$ de los casos (15 de 36), mientras que el desempeño de los demandantes privados fue de un 23\% (9 de 27). Por su parte, los niveles de significación de los coeficientes serían: $0 \%$ para los Litigios Privados $(x 1=0), 5 \%$ para los Litigios Mixtos $(\mathrm{x} 1=1), 0 \%$ para los Litigios Públicos $(\mathrm{x} 1=2)$, y $1 \%$ para el número de audiencias $(\mathrm{x} 2)$. 
Suprema corresponden a casos con valores atípicos en cuanto al número de audiencias ${ }^{51}$.

En definitiva, la FNE es efectivamente un litigante exitoso. Incluso en el espacio donde su desventaja con los demandantes privados pareciera ser mayor, la probabilidad de condena sería cercana a un 70\%. Pese a lo anterior, los resultados también sugieren que el comportamiento de ambos tipos de litigantes es diferente. En otros términos, si la sociedad pudiera elegir a quien confiar cada caso, su decisión debiera reflejar que no existe un mecanismo claramente dominante. Tratándose de casos que se presentan como relativamente pacíficos, ya sea en razón de la claridad de los hechos o del valor de lo disputado, la víctima quedaría mejor en manos de la FNE. En contraste, respecto de casos donde pareciera que la disputa va escalar, los demandantes privados ofrecen una mejor alternativa.

\section{EL PROBLEMA DE LA COLUSIÓN}

Las diferencias apuntadas pueden traducirse en una fortaleza del sistema de fiscalización, siempre y cuando los organismos públicos y los demandantes privados actúen complementariamente. Cuando concurran respecto de una misma clase de casos, la idea es que la variabilidad de los demandantes privados complemente la uniformidad de la FNE, y viceversa. Ahora bien, esta complementariedad también puede operar mediante una división del trabajo, donde cada tipo de agente se especializa en perseguir cierta clase de ilícitos. En materia de libre competencia, ello podría funcionar con los órganos públicos dedicándose a litigar preferentemente ilícitos multilaterales, típicamente colusión, mientras los demandantes privados se concentrarían en ilícitos unilaterales, típicamente abuso de posición dominante ${ }^{52}$.

Atendido que la base de datos del TDLC consigna una variable categorial identificando el tipo de ilícito perseguido, es posible determinar si el referido patrón de selección entre los litigantes es efectivo ${ }^{53}$. Según

51 De 58 fallos pronunciados por la Corte Suprema, solamente un 14\% corresponden a revocaciones respecto de lo resuelto por el TDLC (6 revocando una sentencia condenatoria, y otras 2 un fallo absolutorio). Intentar formular conclusiones generales sobre la base de esta microtendencia, sin embargo, lleva implícito un grado importante de extrapolación toda vez que los juicios más disputados tienden a generar un mayor número de apelaciones.

52 Podría objetarse que esta tendencia también cuestionaría el análisis propuesto, ya que los ilícitos multilaterales involucran más demandados, y quizás por ello, un mayor número de audiencias. No obstante, la correlación entre el número de demandados y el número de audiencias está lejos de ser significativa. Utilizando la muestra descrita en supra, nota 23, la correlación entre el número de demandados y el número de audiencias fue de 0.33 , con un valor p del 34\% para la hipótesis nula de que dicha correlación es cero.

53 Para estos efectos, se consideraron como unilaterales las conductas que la base de datos de TDLC identifica como "abuso de posición dominante", "precios predatorios", "competencia 
se muestra en la Tabla 4, los demandantes privados muestran un patrón de selección donde priman los ilícitos unilaterales en general, y el abuso de posición dominante en particular. Más de dos tercios de las demandas privadas se relacionan con conductas unilaterales, y cerca la mitad con casos de dominancia. Algo similar sucede con los litigios mixtos, lo cual resulta consistente con el hecho de que en este tipo de procedimientos sea un agente privado quien toma la decisión inicial de demandar.

En contraste, la FNE no pareciera tener preferencia alguna en la selección de casos. El número de requerimientos aparece equitativamente distribuido, tanto entre conductas unilaterales y multilaterales, como entre casos de colusión y de dominancia ${ }^{54}$. Ello revela un aspecto preocupante. En la medida que tanto agentes públicos como privados concurren sobre un mismo grupo de casos, la intuición desarrollada en este trabajo sugiere que la interacción entre ambos debiera llevar a que cada uno corrija los vicios del otro. Sin embargo, ello no sucede con los casos de colusión, donde cerca del $80 \%$ de las causas fue iniciada mediante un requerimiento de la FNE. Teniendo en cuenta que la colusión suele considerarse como el ilícito más grave en materia de libre competencia, esta dependencia de la fiscalización pública implica que cualquier problema en el funcionamiento de la FNE generaría un problema importante en un área clave del sistema de fiscalización.

\section{Tabla 4: Patrones de Selección de los Litigantes (Tipo de Litigio y Tipo de Ilícito)}

\begin{tabular}{llll|l}
\hline \hline & $\begin{array}{l}\text { Público } \\
\text { № (\%) }\end{array}$ & $\begin{array}{l}\text { Mixto } \\
\text { № (\%) }\end{array}$ & $\begin{array}{l}\text { Privado } \\
\text { № (\%) }\end{array}$ & TOTAL \\
\hline Unilateral & $22(11.4 \%)$ & $9(4,7 \%)$ & $105(54,4 \%)$ & $136(71,2 \%)$ \\
Dominancia & $16(8,3 \%)$ & $5(2,6 \%)$ & $59(30,6 \%)$ & $80(41,8 \%)$ \\
Multilateral & $22(11.4 \%)$ & $1(0,5 \%)$ & $32(16,6 \%)$ & $55(28,7 \%)$ \\
Colusión & $19(9,8 \%)$ & - & $4(2,1 \%)$ & $23(12 \%)$ \\
\hline TotaL & $39(23,4 \%)$ & $9(5,4 \%)$ & $119(71,3 \%)$ & $167(100 \%)$ \\
\hline \hline
\end{tabular}

desleal” o "incumplimiento de resolución”. La clasificación de esta última obedece a que corresponde al incumplimiento de las condiciones fijadas para una fusión, las que a su vez típicamente son impuestas como una forma de evitar situaciones de dominancia. Ver, Nehme, Nicole, y Mordoj, Benjamín (2012) "Diseños Institucionales de Control de Concentraciones". Revista Estudios Públicos, N¹25, pp. 92-96). Por su parte, se consideraron multilaterales las conductas registradas como "colusión", "barreras a la entrada" y "actos de autoridad". En el caso de estos dos últimos, la clasificación obedece a un análisis cualitativo sobre el número de partes involucradas.

54 Si sumamos los litigios mixtos, la participación de la FNE seguiría un patrón similar al de los demandantes privados, aunque la preferencia por ilícitos unilaterales y de dominancia sería menos pronunciada que en el caso de los demandantes privados. El número de causas por conductas unilaterales superaría a las multilaterales en un $20 \%$ (29 a 19), mientras que los casos de dominancia superarían a los de colusión en un 6\% (18 a 16). 
Nota: Para cada tipo de ilícito, la línea inferior muestra la categoría más relevante. La clasificación de las conductas fue realizada conforme al procedimiento indicado en el cuerpo de este documento. Los datos fueron obtenidos de la base de datos del TDLC, disponible en www.tdlc.cl

Desde una perspectiva cualitativa, confiar en la FNE como único mecanismo de control podría resultar problemático en atención a las señales que envía nuestra comunidad jurídica. En primer lugar, es importante tener en cuenta que la ausencia de litigación privada en materia de colusión pareciera responder a la estructura de costos de agencia subyacentes, y por ello, es una tendencia que debiera mantenerse en el tiempo. Quienes sufren las consecuencias de la fijación cartelizada de precios son los consumidores, de modo que el financiamiento de un litigio privado sobre esta materia requiere reunir un gran número de víctimas dispersas. A esto se agrega que las acciones de clase y otros mecanismos procesales para favorecer la litigación representativa han demostrado ser particularmente ineficaces en nuestro país ${ }^{55}$.

En segundo lugar, de un tiempo a esta parte se ha instalado en la doctrina la idea de que los principios del proceso penal deben aplicarse a todos los procedimientos administrativos de sanción, incluyendo en esta última categoría los litigios donde un organismo público persigue la imposición de una multa. Dentro del ámbito de la libre competencia, dicho razonamiento ha sido traído a colación especialmente a propósito de ilícito de colusión ${ }^{56}$. Sin perjuicio de los argumentos constitucionales esgrimidos, lo cierto es que extender estas garantías típicamente involucra limitar la efectividad de la FNE como organismo de fiscalización ${ }^{57}$.

La experiencia en derecho comparado muestra que este tipo de situaciones puede introducir un sesgo indeseable en la manera en que la FNE decide a quién fiscalizar. En particular, una respuesta racional al aumento en los estándares probatorios, sería que los organismos públicos tiendan

55 De hecho, resulta paradójico que los únicos casos donde las víctimas de una colusión hayan recibido compensaciones correspondan a procesos encabezados por el Servicio Nacional del Consumidor, esto es, un organismo público. Ver, Engel, Eduardo, Muñoz, Ernesto, y Repetto, Andrea (2013) Hacia Una Sociedad Sin Abusos: Propuestas para una Protección Eficaz de los Consumidores. Santiago: Informes Espacio Público, p. 14-15

56 Eyzaguirre, Cristobal, y Grunberg, Jorge (2008) "Colusión Monopólica: Prueba de la Colusión, Paralelismo de Conductas y Factores Añadidos”. Anales de Derecho UC, N², pp. 52-54; y Tapia, Javier (2010) La Prohibición de la Colusión en el Derecho Chileno y Comparado. Informe en Derecho, "Requerimiento de la FNE en contra de ACHAP A.G, y otros", p. 12-14.

57 Montt, Santiago (2009) El Tribunal de Defensa de la Libre Competencia como ente regulador del comercio: una mirada desde las politicas públicas. Documentos de trabajo. Santiago: Centro de Regulación y Competencia, p. 10. Una objeción similar, pero respecto del antiguo ilícito penal que sancionaba las violaciones a la libre competencia, en Depolo, Radoslav (1997) "El Régimen Jurídico de Defensa de la Competencia en Chile. Algunas Proposiciones para su Despenalización”. Revista de Derecho PUCV, N¹8, p. 437. 
a focalizarse en empresas más pequeñas o ilícitos de menor cuantía ${ }^{58}$. En ambos casos, los demandados tendrían una menor disponibilidad de recursos para explotar el costo adicional de extender las garantías penales como una ventaja procesal. Por lo tanto, depender exclusivamente de la FNE y simultáneamente erosionar sus capacidades de actuación, debiera aumentar el número de carteles que quedan impunes.

En cualquier caso, también es importante tener en cuenta que la magnitud del problema es moderada. Aunque resulta imposible determinar qué fracción de los ilícitos son efectivamente detectados, expertos de distintos sectores y orientaciones políticas han manifestado su conformidad con el actual nivel de cobertura del sistema de fiscalización ${ }^{59}$. En el fondo, la presencia de patrones de selección entre los litigantes no resulta preocupante en sí misma, sino en atención a la dirección que está tomando el debate sobre políticas públicas en esta materia. Dicho de otro modo, debemos ser conscientes de que si exigimos a la FNE fallar por el lado de la cautela, el mercado de los litigantes privados no va a satisfacer ese exceso de demanda por justicia.

\section{CONCLUSIONES}

Desde una perspectiva analítica, este artículo muestra una manera de comprender las diferencias entre la FNE y los litigantes privados en términos de su estructura de costos de agencia. En el caso de los demandantes privados estos varían dependiendo del número de víctimas involucradas, mientras que respecto de organismos públicos los costos están incrustados en su organización burocrática y se mantienen constantes con independencia del tipo de infracción perseguida. Este enfoque provee una explicación plausible para las tendencias existentes en la base de datos del TDLC y de manera más precisa que trabajos previos.

En efecto, si bien la FNE obtiene mejores resultados en una gran cantidad de casos donde el nivel de intensidad de la disputa es relativamente bajo, en la minoría de casos donde este nivel es relativamente alto, son los demandantes privados quienes muestran mayor efectividad. Estos resultados se mantienen si se incorpora el resultado de los recursos de re-

58 Utilizando un análisis de regresión similar al propuesto en este estudio, Cox y THOMAS (2003) 777-779, encontraron evidencia de este tipo de sesgo de vigilancia en el fiscalizador del mercado de valores de Estados Unidos.

59 Aroca, Dafne (2010) Análisis de la Independencia de los Organismos Antimonopolio en Chile. Tesis de Máster. Santiago: Departamento de Ingeniería Industrial de la Universidad de Chile, p. 45-57, realizó hace algún tiempo una serie de entrevistas de investigación a expertos en libre competencia. La lista de entrevistados incluyó a Eduardo Saavedra, María de la Luz Domper, Nicole Nehme, Ricardo Jungmann, Felipe Irarrázabal, Pablo Serra, Alejandro Ferreiro, Enrique Vergara, Aldo González y Ricardo Sanhueza. 
clamación ante la Corte Suprema. En general, el sistema de fiscalización exhibe un grado saludable de interacción entre agentes públicos y privados. Los demandantes privados efectivamente muestran una tendencia hacia la instrumentalización del proceso mediante casos que terminan en desistimiento o archivo, pero los niveles alcanzados son sustancialmente menores a los de la justicia civil. Por otro lado, la FNE es un litigante exitoso, aun cuando tenga un peor desempeño que los privados en casos donde la intensidad de la disputa es mayor.

Desde una perspectiva metodológica, el modelo secuencial propuesto en este trabajo concibe el litigio como un proceso de acumulación de evidencia y argumentos, con un juez que revisa diagonalmente el expediente al momento de dictar sentencia. Esta característica entrega una mejor representación de la naturaleza burocrática -o incluso kafkiana- de los litigios en nuestro país. También permite destacar que los mecanismos de fiscalización pública y privada no deben ser tratados como sustitutos. Los demandantes privados debieran ser responsables de la mayor parte de los litigios, aunque en términos proporcionales sean efectivos solamente en una pequeña fracción.

Lo importante, es que su estructura de costos de agencia les permite responder de mejor manera en litigios particularmente complejos y disputados. Al revés, la FNE interviene menos en términos absolutos, pero es mucho más efectiva en términos relativos. Más aún, los organismos públicos son menos susceptibles a desarrollar un sesgo de especialización y menos proclives a instrumentalizar el litigio. De este modo, ambos mecanismos actúan como complementos estratégicos, por lo que fortalecer uno a expensas del otro parece derechamente una mala idea.

Finalmente, podría argumentarse que existen aspectos idiosincráticos respecto de los litigios sobre libre competencia, o respecto de los tribunales chilenos, que limitan el alcance de las conclusiones. No obstante, el enfoque desarrollado en este trabajo es similar al que utiliza la literatura reciente sobre acciones representativas en el mercado de valores. En lugar de tener costos de agencia que varían dependiendo del tipo de ilícito, en esta otra sede los cambios se relacionan con la existencia de inversionistas institucionales, quienes estarían en condiciones de construir economías de escala para coordinar a las víctimas y su comportamiento respondería a ciertas características de su burocracia interna. Algo similar sucede con el patrón de selección de casos. En el ámbito del mercado de valores la literatura observa que la estructura de incentivos de los organismos públicos puede empujarlos a desarrollar un sesgo hacia juicios más cortos, menos disputados y que involucren a empresas más pequeñas. Al contrario, los incentivos de los demandantes privados serían perseguir bolsillos profundos y empresas de mayor tamaño, aún cuando ello suponga un juicio relativamente más intenso. 


\section{BIBLIOGRAFÍA}

- Aroca, Dafne (2010) Análisis de la Independencia de los Organismos Antimonopolio en Chile. Tesis de Máster no publicada, Departamento de Ingeniería Industrial - Universidad de Chile.

- Arrow, Keneth (1985) "The Economics of Agency". En J. Pratt y R. Zeckhauser (Eds.), Principals and agents: The structure of business. Massachussets: Harvard Business Press.

- Baird, Douglas, Gertner, Robert, y Picker, Randal (1998) Game Theory and the Law. Cambridge, Massachusetts: Harvard University Press.

- Bebchuk, Lucian, y Kaplow, Louis (1993). "Optimal Sanctions and Differences in Individuals' Likelihood of Avoiding Detection". International Review of Law and Economics, 13 (2), 217-224.

- Becker, Gary (1968). "Crime and Punishment: An Economic Approach". Journal of Political Economy, 76 (2), 169-217.

- Becker, Gary, y Stigler, George (1974). "Law Enforcement, Malfeasance, and Compensation of Enforcers". Journal of Legal Studies, 3, 1-18.Bernardo, A., Talley, E., y Welch, I. (2000). A Theory of Legal Presumptions. Journal of Law, Economics, and Organization, 16 (1), 1-49.

- Black, Bernard (1992). "Agents Watching Agents: The Promise of Institutional Investor Voice”. UCLA Law Review, 39 (4), 811-893.

- Bourjade, Sylvain, Rey, Patrick, y Seabright, Paul (2009). "Private Antitrust Enforcement in the Presence of Pre-Trial Bargaining". The Journal of Industrial Economics, 57 (3), 22-1821.

- Breit, William, y Elzinga, Keneth (1974). "Antitrust enforcement and economic efficiency: The uneasy case for treble damages". Journal of Law \& Economics, 17, 329.

- Coffee, John (1986). "Understanding the Plaintiff's Attorney: The Implications of Economic Theory for Private Enforcement of Law Through Class and Derivative Actions". Columbia Law Review, 86, 669.

- Cooter, Robert, y Rubinfeld, Daniel (1989). "Economic Analysis of Legal Disputes and Their Resolution". Journal of Economic Literature, 28, 1067-1097.

- Cox, James, y Thomas, Randall (2003). "SEC Enforcement Heuristics: An Empirical Inquiry”. Duke Law Journal, 737-779. $-(2004)$. "Public and Private Enforcement of the Securities Laws: Have Things Changed Since ENRON". Notre Dame Law Review, 80, 893. 
$\ulcorner$ (2006). Does the Plaintiff Matter?: "An Empirical Analysis of Lead Plaintiffs in Securities Class Actions". Columbia Law Review, 106, 1587-1640.

- Cseres, Katalin (2005). Competition Law and Consumer Protection. London, England: Kluwer Law International.

- Damaska, Mirjan (2000). Las Caras de la Justicia y el Poder del Estado: Análisis Comparado del Proceso Legal. Editorial Jurídica de Chile.

- Depolo, Radoslav (1997). “El Régimen Jurídico de Defensa de la Competencia en Chile. Algunas Proposiciones para su Despenalización”. Revista de Derecho (PUC - Valparaíso), 18, 435441 .

- Emons, Winand, y Fluet, Claude (2011). Adversarial Versus Inquisitorial Testimony. Descargado de http://escholarship.org/uc/ item/446030wd (Law and Economics Workshop, Berkeley Program in Law and Economics)

- Engel, Eduardo, Muñoz, Ernesto, y Repetto, Andrea (2013). "Hacia Una Sociedad Sin Abusos: Propuestas para una Protección Eficaz de los Consumidores”. Informes Espacio Público, 1.

- Eyzaguirre, Cristobal, y Grunberg, Jorge (2008). "Colusión Monopólica: Prueba de la Colusión, Paralelismo de Conductas y Factores Añadidos". Anales de Derecho UC, 2.

- Fisher, Franklin (1980). "Multiple Regression in Legal Proceedings". Columbia Law Review, 80 (4), 702-736.

- Fudenberg, Drew, y Tirole, Jean (1991). Game Theory. Cambridge, Massachusetts: MIT Press.

- Galanter, Mark (1974). "Why The "Haves" Come Out Ahead: Speculations on the Limits of Legal Change". Law \& Society Review, 9 (1), 95-160.

- García, José Francisco, y Leturia, Francisco José (2006). “Justicia Civil: Diagnóstico, Evidencia Empírica y Lineamientos para una Reforma”. Revista Chilena de Derecho, 33 (2), 345-384.

- Garoupa, Nuno (1997a). "A Note on Private Enforcement and Type-I Error". International Review of Law and Economics, 17 (3), 423-429.

- (1997b). "The Theory of Optimal Law Enforcement". Journal of Economic Surveys, 11 (3), 267-295.

- Ginsburg, Douglas (2005). "Comparing Antitrust Enforcement in the United States and Europe". Journal of Competition Law and Economics, 1 (3), 427-439.

- González, Aldo, y Micco, Alejandro (2014). "Private versus public enforcement: Evidence from Chile". Journal of Competition Law and Economics, 10 (4). 
- González, Aldo, Micco, Alejandro, y Caicha, Constanza (2013). "El Impacto de la persecución pública en los juicios sobre libre competencia en Chile”. Estudios Públicos, 132, 39-69.

- HaYeк, Friedrich (1945). "The use of knowledge in society". The American Economic Review, 35 (4), 519-530.

- Hirshleifer, Jack, y Osborne, Evan (2001). “Truth, Effort, and the Legal Battle”. Public Choice, 108 (1-2), 169-195.

- Jensen, Michael, y Meckling, William (1976). "Theory of the firm: Managerial behavior, agency costs and ownership structure". Journal of Financial Economics, 3 (4), 305-360.

- Kaplow, Louis (1990). "A Note on the Optimal Use of Nonmonetary Sanctions". Journal of Public Economics, 42 (2), 245247.

- Kaplow, Louis, y Shavell, Steven (1994). "Accuracy in the Determination of Liability". Journal of Law and Economics, 37 (1), $1-15$.

- Landes, William, y Posner, Richard (1975). "The Private Enforcement of Law”. Journal of Legal Studies, 4, 1.

- Macey, Jonathan, y Miller, Geoffrey (1991). "The Plaintiffs' Attorney's Role in Class Action and Derivative Litigation: Economic Analysis and Recommendations for Reform”. University of Chicago Law Review, 58, 1.

- Maggi, Giovanni, y Rodríguez-Clare, Andrés (1995). "Costly Distortion of Information in Agency Problems". RAND Journal of Economics, 26 (4), 675-689.

- Martini, Gianmaria, y Rovesti, Cinzia (2004). "Antitrust Policy and Price Collusion: Public Agencies vs. Delegation". Recherches Économiques de Louvain/Louvain Economic Review, 70, 127-151.

- McAfee, Preston, Mialon, Hugo, y Mialon, Sue (2008). "Private v. Public Antitrust Enforcement: A Strategic Analysis". Journal of Public Economics, 92 (10), 1863-1875.

- Mery, Rafael (2006). Una Aproximación Teórica y Empírica a la Litigación Civil en Chile. (Documento de Trabajo No. 7, Centro de Investigación y Desarrollo Empresarial UDP).

- Montt, Santiago (2009). El Tribunal de Defensa de la Libre Competencia Como Ente Regulador del Comercio: Una Mirada Desde las Politicas Públicas. (Documentos de Trabajo No. 1, Centro de Regulación y Competencia - Universidad de Chile).

- Nerme, Nicole, y Mordoj, Benjamín (2012). "Diseños Institucionales de Control de Concentraciones". Revista Estudios Públicos, 125, 87-137.

- Osborne, Martin, y Rubinstein, Ariel (1994). A Course in Game Theory. Cambridge, Massachusetts: MIT Press. 
- Pardow, Diego (2012). "La Experiencia Chilena Disuadiendo Ilícitos Corporativos”. Derecho Público Iberoamericano, 1 (1), 55-85.

- Paredes, Ricardo (1995). "Jurisprudencia de las Comisiones Antimonopolios en Chile”. Revista Estudios Públicos, 58, 227-320.

- Polinsky, Mitchell (2011). An Introduction to Law and Economics. Aspen Publishers.

- Polinsky, Mitchell, y Shavell, Steven (1992). "Enforcement Costs and the Optimal Magnitude and Probability of Fines". Journal of Law and Economics, 35 (1), 133-148.

- (2000). The Economic Theory of Public Enforcement of Law. Journal of Economic Literature, 38 (1), 45-76.

- Posner, Richard (1976). Antitrust Law: An Economic Perspective. Chicago, Illinois: University of Chicago Press.

- Priest, George, y Klein, Benjamin (1984). "The Selection of Disputes for Litigation". The Journal of Legal Studies, 13 (1), 1-56.

- Rose-Ackerman, Susan (1986). "Reforming Public Bureaucracy through Economic Incentives?" Journal of Law, Economics and Organization, 2 (1), 131-61.

- Salop, Steven, y White, Lawrence (1985). "Economic Analysis of Private Antitrust Litigation". Georgetown Law Journal, 74, 10011071.

- Schwartz, Warren, y Wickelgren, Abraham (2011). "Optimal Antitrust Enforcement: Competitor Suits, Entry, and Post-entry Competition”. Journal of Public Economics, 95 (7), 967-972.

- Segal, Ilya, y Winston, Michael (2006). "Public vs. Private Enforcement of Antitrust Law: A Survey" (Inf. Téc. n.o 335). Stanford Law \& Economics Olin Working Paper.

- Shapiro, Susan (2005). "Agency Theory". Annual Review of Sociology, 31, 263-284.

- Shavell, Steven (1991). "Specific versus General Enforcement of Law”. Journal of Political Economy, 99 (5), 1088-1108.

- (1993). "The Optimal Structure of Law Enforcement". Journal of Law and Economics, 255-287.

- Smith, James, y Vaughan, Michael (1986). "Economic Welfare, Price and Profit: The Deterrent Effect of Alternative Antitrust Regimes". Economic Inquiry, 24 (4), 615-629.

- Stigler, George (1970). "The Optimum Enforcement of Laws". The Journal of Political Economy, 78 (3), 526-536.

- Talley, Eric (2012). "Law, Economics, and the Burden (s) of Proof". En J. Arlen (Ed.), Research Handbook on the Economics of Torts. Nueva York: Edward Elgar Publications. 
- Tapia, Javier (2010). La Prohibición de la Colusión en el Derecho Chileno y Comparado. (Informe en Derecho, "Requerimiento de la FNE en contra de ACHAP A.G, y otros").

- Tarziján, Jorge, y Hevia, José (2005). "Jurisprudencia Sobre Precios Predatorios en Chile: ¿Han Sido Uniformes Los Criterios Aplicados?" Revista ABANTE, 8 (2), 59-85.

- Trebilcock, Michael, y Roach, Kent (1996). "Private Enforcement of Competition Laws". Osgoode Hall Law Journal, 34, 461.

- Tullock, Gordon (1980). "Efficient Rent-Seeking". En James Buchanan, Robert Tollison, y Gordon Tullock (Eds.), Toward a Theory of the Rent-seeking Society. Texas A \& M University Press.

- VAldés, Domingo (2006). Libre Competencia y Monopolio. Santiago de Chile: Editorial Jurídica.

- Vallejo, Rodrigo, y Guiloff, Matías (2014). Ni Juez, Ni Parte: La Competencia Sancionadora de la Administración y la Metodología del Derecho Administrativo. (Jornadas de Derecho Administrativo)

- Vargas, Juan, Peña, Carlos, y Correa, Jorge (2001). El Rol del Estado y el Mercado en la Justicia. Santiago de Chile: Universidad Diego Portales.

- Wickelgren, Abraham (2012). "Issues in Antitrust Enforcement". En Einer Elhauge (Ed.), Research Handbook on the Economics of Antitrust Law. Edward Elgar Publishing.

- Williamson, Oliver (1985). The Economic Institutions of Capitalism: Firms, Markets, Relational Contracting. Nueva York: Free Press. 